\title{
Effects of the Largest Lake of the Tibetan Plateau on the Regional Climate
}

\section{Su, Dongsheng}

2020-11-27

Su , D , Wen , L , Gao , X, Leppäranta , M , Song , X, Shi , Q \& Kirillin , G 2020 , ' Effects of the Largest Lake of the Tibetan Plateau on the Regional Climate ' , Journal of Geophysical Research : Atmospheres , vol. 125 , no. 22 , ARTN e2020JD033396 . https://doi.org/10.1029/2020JD033396

http://hdl.handle.net/10138/330474

https://doi.org/10.1029/2020JD033396

publishedVersion

Downloaded from Helda, University of Helsinki institutional repository.

This is an electronic reprint of the original article.

This reprint may differ from the original in pagination and typographic detail.

Please cite the original version. 


\section{JGR Atmospheres}

\section{RESEARCH ARTICLE \\ 10.1029/2020JD033396 \\ Effects of the Largest Lake of the Tibetan Plateau on the Regional Climate}

Key Points:

- The coupled lake-atmosphere mode after adjusting four key parameters performs well in quantifying the lake's regional climate effects

- Qinghai Lake decreased the local precipitation during April-June while increased that during July-November

- Throughout the simulation period, precipitation declined slightly in the north and rose greatly in the south due to the lake's presence

Correspondence to:

L. Wen,

wlj@lzb.ac.cn

Citation:

Su, D., Wen, L., Gao, X., Leppäranta, M., Song, X., Shi, Q., \& Kirillin, G.

(2020). Effects of the largest lake of the Tibetan Plateau on the regional climate. Journal of Geophysical Research: Atmospheres, 125, e2020JD033396. https://doi.org/10.1029/2020JD033396

Received 29 JUN 2020

Accepted 25 OCT 2020

Accepted article online 31 OCT 2020

Author Contributions:

Conceptualization: Dongsheng $\mathrm{Su}$,

Lijuan Wen

Data curation: Dongsheng Su, Xingyu

Song, Qianqian Shi

Formal analysis: Dongsheng $\mathrm{Su}$,

Lijuan Wen, Georgiy Kirillin

Funding acquisition: Lijuan Wen

Investigation: Xiaoqing Gao,

Qianqian Shi

Methodology: Dongsheng Su, Xingyu

Song

Project administration: Lijuan Wen

Resources: Lijuan Wen, Xiaoqing Gao

Supervision: Lijuan Wen, Xiaoqing

Gao

Validation: Lijuan Wen, Xiaoqing

Gao, Matti Leppäranta, Georgiy Kirillin

Visualization: Dongsheng $\mathrm{Su}$

Writing - original draft: Dongsheng Su

Writing - review \& editing:

Dongsheng Su, Lijuan Wen, Matti

Leppäranta, Georgiy Kirillin

(C)2020. American Geophysical Union. All Rights Reserved.

\author{
Dongsheng Su${ }^{1,2}$ iD, Lijuan Wen ${ }^{1}$ (D), Xiaoqing Gao ${ }^{1}$ iD, Matti Leppäranta ${ }^{3}$, Xingyu Song ${ }^{4}$, \\ Qianqian $\mathrm{Shi}^{5}$, and Georgiy Kirillin' ${ }^{6}$ iD \\ ${ }^{1}$ Key Laboratory of Land Surface Process and Climate Change in Cold and Arid Regions, Northwest Institute of Eco- \\ Environment and Resources, Chinese Academy of Sciences, Lanzhou, China, ${ }^{2}$ College of Earth and Planetary Sciences, \\ University of Chinese Academy of Sciences, Beijing, China, ${ }^{3}$ Institute of Atmospheric and Earth Sciences, University of \\ Helsinki, Helsinki, Finland, ${ }^{4}$ School of Atmospheric Sciences, Chengdu University of Information Technology, Chengdu, \\ China, ${ }^{5}$ College of Resources and Environmental Sciences, Gansu Agricultural University, Lanzhou, China, ${ }^{6}$ Department \\ of Ecohydrology, Leibniz-Institute of Freshwater Ecology and Inland Fisheries, Berlin, Germany
}

Abstract Qinghai Lake is the largest lake in China. However, its influence on the local climate remains poorly understood. By using an atmosphere-lake coupled model, we investigated the impact of the lake on the local climate. After the adjustment of four key parameters, the model reasonably reproduced the lake-air interaction. Superimposed by the orographic effects on lake-land breeze circulation, the presence of the lake enhanced precipitation over the southern part of the lake and its adjacent land, while slightly reduced precipitation along the northern shore of the lake. The lake effect on local precipitation revealed a distinct seasonal and diurnal variability, reducing precipitation in May $(-6.6 \%)$ and June $(-4.5 \%)$ and increasing it from July (5.7\%) to November (125.6\%). During the open water season, the lake's daytime cooling effect weakened and the nighttime warming effect strengthened, affecting spatial distribution and intensity of lake-induced precipitation. In early summer, precipitation slightly decreased over the north part of the lake due to the lake's daytime cooling. In turn, lake-induced nighttime warming increased precipitation over the southern section of the lake and its adjacent land. With the start of the autumn cooling in September, heat and moisture fluxes from the lake resulted in precipitation increase in both daytime and nighttime over the entire lake. In October, the background atmospheric circulation coupled with the strong lake effects lead to a small amount but high proportion of lake-induced precipitation spreading evenly over the lake.

\section{Introduction}

Lakes, especially the large ones, significantly modify regional weather and climate, due to their larger heat capacity, lower albedos, and smaller roughness compared to the surrounding land area, and are strong sources of atmospheric moisture during the open water period (Bates et al., 1993; Bonan, 1995; Changnon \& Jones, 1972; Long et al., 2007; Scott \& Huff, 1996). Because they influence local climate, lakes have attracted broad research attention during the last decades. The lake effects vary significantly among different regions, depending on the background atmospheric circulation, lake characteristics, and the surrounding topography (Argent et al., 2015; Wen et al., 2015).

For example, the largest freshwater lake system in the world-Laurentian Great Lakes-can induce snowstorms over the downwind area, resulting in casualties, economic losses, and transportation disruptions. Hence, investigations of the lake effects on the local climate are urgently needed (Kristovich et al., 2000; Theeuwes et al., 2010). Previous studies have shown that in the cold season from September to March, the surface temperature of the Great Lakes is higher than the air temperature, triggering convective instability and resulting in increased precipitation over the lakes. In turn, in the warm season, from April to August, the lake surface temperature is lower than the air temperature, inhibiting local convective precipitation in the afternoon (Changnon, 1961; Jiusto \& Kaplan, 1972; Notaro et al., 2013; Wilson, 1977). The study of Bates et al. (1993) indicated that the Great Lakes contribute up to $25 \%$ to the local precipitation in December and $50-70 \%$ over the major snow belts downwind from the lakes. Scott and Huff (1996) found that the Great Lakes decreased precipitation by $10-20 \%$ on the downwind shores in summer and enhanced it up to $100 \%$ in winter. A diurnal cycle with a distinct morning maximum and an afternoon/evening 
minimum in the lake-effect precipitation frequency was observed over the Great Lakes by Kristovich and Spinar (2005). Modeling studies on European lakes demonstrated that they induced a climate warming for all seasons and enhanced convective precipitation over southern Finland during late summer and early autumn (Eerola et al., 2014; Samuelsson et al., 2010). Iakunin et al. (2018) found that the Alqueva reservoir in western Europe induces breeze effects and redistributes the water vapor over the lake. The African Great Lakes produce a cooling effect and inhibit lake surface convection during daytime with an opposite effect at night, while the annual precipitation is almost doubled over the lake (Thiery et al., 2015). Lake Malawi in East Africa significantly increases precipitation over the lake and the neighboring areas during the summer rain season (Diallo et al., 2018). Great Bear Lake and Great Slave Lake, the two largest lakes in Canada, decrease the surface temperature, the sensible heat flux, the latent heat flux, and air humidity in July-August, with the opposite effect in October (Long et al., 2007).

The lake system of the Tibetan Plateau (TP), which is known as "the world water tower" (Xu et al., 2008), comprises more than a half of the total lake coverage in China (Ma et al., 2010; G. Q. Zhang et al., 2014). Earlier studies have shown that precipitation over the TP has increased significantly in recent years, and most lakes on the TP have shown an obvious expansion trend (Lei et al., 2014; Liao et al., 2013). Due to the extreme climate over the TP, characterized by low air density, low temperature, and strong solar radiation (Y. X. Gao et al., 1981; Ma et al., 2009), the lakes produce strong effects on the regional air-land interaction and climate. However, the harsh environmental conditions on the TP have caused a lack of continuous observations, particularly over the lakes, making it difficult to assess the influence of lakes on the regional scales. Compared with the lakes of other regions, studies on the regional climate effects of the TP lakes are still rare. Gerken et al. (2013) found that Nam Co, one of the large and well-investigated lakes on the TP, could develop a lake-breeze system triggering moist and deep convection by interactions with topography and background wind. The lake cooling and heating effects in different seasons can influence the spatial distribution of precipitation (Dai, Yao, et al., 2018). An increase in precipitation up to $60 \%$ was simulated over Nam Co and its downwind area in October (Dai, Wang, et al., 2018). Lake surface temperatures have a considerable influence on precipitation over the TP: Precipitation, especially the convective precipitation, increases with increasing lake surface temperature (X. Zhang et al., 2016), significantly enhancing the precipitation recycling ratio over the TP (Y. Gao, Chen, Miguez-Macho, \& Li, 2020). The warm surface of Ngoring Lake and Gyaring Lake on the TP induces a low-level horizontal convergence and updraft over the lakes, providing energy and vapor for the development of convection, and increases precipitation over the lake and nearby region from July to October (Wen et al., 2015). Herewith, the impact of the TP lakes on climate is closely related to lake intrinsic features, local terrain, and background atmospheric circulation (Wu et al., 2019).

Qinghai Lake has the largest water area on the TP and in China, making it to a huge local water vapor source and a heat accumulator in the relatively dry, cold, and strongly insolated climate conditions of the TP. However, the impact of the lake on the atmospheric dynamics and the regional precipitation is poorly studied and remains rather uncertain. Previous modeling studies focused on limited periods and were unable to reveal the seasonal evolution of the lake effect on the local climate (Lv et al., 2007). Moreover, the regional climate model (RCM) used before was not coupled to a lake model, and the lake surface temperature was interpolated from the sea surface temperatures in the input data (Chen et al., 1995; Lv et al., 2007). This interpolation approach is unable to adequately describe the lake surface temperature variation at both seasonal and daily scales, resulting in large simulation errors in the lake-atmosphere interaction (Samuelsson et al., 2010).

Two-way coupling of an RCM with a lake model can significantly increase the accuracy of simulated lake surface temperature (Le Moigne et al., 2016; Mallard et al., 2014; Xue et al., 2017), improving predictions of lake-atmosphere interactions. Recently, studies were performed on the TP lakes Nam Co and Ngoring using the Weather Research and Forecasting (WRF) model coupled to a lake model (Ao et al., 2018; Dai, Wang, et al., 2018; Wen et al., 2015). The lake model in these studies was represented by the Community Land Model lake module (hereafter CLM-Lake). The latter is a one-dimensional (1-D) mass and energy balance model stemming from the Hostetler lake model (Hostetler et al., 1993), modified by Subin et al. (2012), and calibrated and coupled with WRF by Gu et al. (2015). The CLM-Lake model utilizes a layered lake representation with 25 vertically homogeneous layers in total, 10 of them reserved for the lake water column. The fixed discrete vertical resolution has apparent disadvantages for lake representation in regional to global climate models: On one hand, the fixed low number of layers results in a coarse resolution of the vertical 


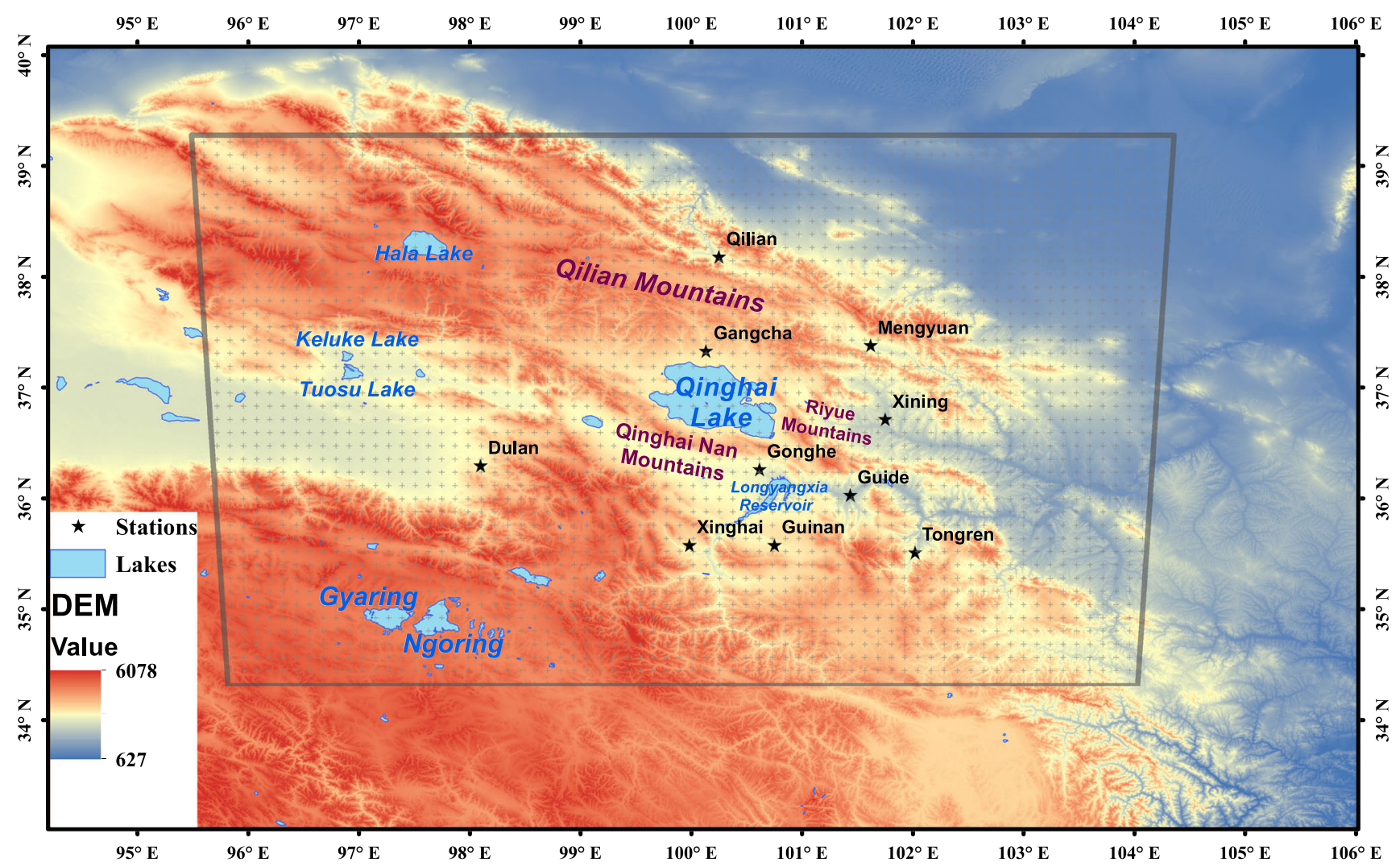

Figure 1. Location and topography of Qinghai Lake and its surrounding areas. The inner black box denotes the simulation domain.

thermal structure within a lake with corresponding errors in the air-lake heat and mass fluxes, especially in large and deep lakes. On the other hand, an increase in vertical resolution requires a multifold increase in computing resources, which are limited for complex climate models. An alternative approach to lake parameterization in land-atmosphere interaction is implemented in the 1-D lake model FLake, which uses a highly parameterized self-similarity solution for the heat transport within the lake water column (Kirillin, 2010; Kirillin et al., 2011; Mironov, 2008). Being numerically efficient and capturing well the crucial physical features of the lake heat and mass transport, FLake has been implemented to date in the majority of numerical weather prediction systems and climate models including CLM and WRF (Gula \& Peltier, 2012; Iakunin et al., 2018; Samuelsson et al., 2010; Thiery et al., 2015). FLake also performed better than the CLM-Lake model in simulating the upper layer temperature over a TP lake (Huang et al., 2019), resulting in a better representation of the lake-air interaction.

The purpose of this study is to evaluate the performance of the WRF version coupled to FLake in simulating the lake-air interaction over Qinghai Lake and estimate the effects of the lake on the local precipitation. Compared to previous works at Qinghai Lake, this study quantifies more accurately the lake's climate effects and their seasonal evolution by employing a coupled lake-atmosphere model in a long-term simulation, throughout the entire open water period. Verified by the in situ and satellite observations, the model reproduced the lake surface temperature and precipitation very well after adjustment of four key parameters. According to our results, the impact of the lake on precipitation is not only induced by the temperature differences between the lake and surrounding land but is also influenced by the local topography and the background atmospheric circulation.

\section{Study Area and Data}

Qinghai Lake $\left(36^{\circ} 32^{\prime}-37^{\circ} 15^{\prime} \mathrm{N}, 99^{\circ} 36^{\prime}-100^{\circ} 47^{\prime} \mathrm{E}\right)$ is the largest lake in China located on the northeastern margin of the TP at the height of 3,195 m above sea level, in a valley surrounded by the Datong Mountains, Riyue Mountains, Qinghai Nan Mountains, and Qilian Mountains (Figure 1), with the 
surrounding topography lowering from the northwest to the southeast. It is an endorheic, alkaline brackish lake with a salinity of $\sim 12.5 \mathrm{~g} \mathrm{~L}^{-1}$ and a $\mathrm{pH}$ of $\sim 9.2$ (Deng et al., 2010). The water level of the lake gradually and significantly declined during 1961-2004, at a rate of $-7.6 \mathrm{~cm} \mathrm{year}^{-1}$, and thereafter, it has increased rapidly with a rate of $14 \mathrm{~cm}_{\text {year }}{ }^{-1}$ during 2004-2012, mainly attributed to the increased precipitation in this period (Cui \& Li, 2015; Dong et al., 2019). As a result, the surface area of the lake has varied within the last decades from a minimum of about $4,252 \mathrm{~km}^{2}$ in 2004 to $4,549 \mathrm{~km}^{2}$ in 2018 (Cui et al., 2017), with the characteristic length (west to east) of $104 \mathrm{~km}$ and the width (north to south) of $62 \mathrm{~km}$. The lake is surrounded by several sublakes (Gahai Lake, Haiyan Bay, and Shadao Lake on the east shore and Erhai Lake on the southeast shore) formed during its desiccation in the mid-20th century. The lake has an average depth of $21 \mathrm{~m}$, with the maximum of $27 \mathrm{~m}$. The ice-covered period, which has reduced over the recent decades, starts around December/January and ends in early April with a maximum annual lake ice thickness between 0.6 and $1 \mathrm{~m}$ (Cai et al., 2017).

Qinghai Lake has a drainage area of $29,660 \mathrm{~km}^{2}$; most of the catchment is covered by grazing land, alpine shrubs, and meadows. Twenty-three rivers and streams discharge into Qinghai Lake, but most of them are seasonally intermittent. The lake water budget is mainly contributed by precipitation and runoff from the five largest rivers: the Buha River, the Shaliu River, the Haergai River, the Ganzi River, and the Daotang River. The largest 286-km-long Buha river contributes up to $46.9 \%$ of surface runoff to the lake, while the second-largest Shaliu River contributes around 14.5\% (Chang et al., 2017). About 90\% of the annual rainfall in the lake basin takes place between May and September (G. Q. Zhang et al., 2011).

The daily air temperature and precipitation data measured at the meteorological stations were used to evaluate the simulation results. The data of 10 stations around Qinghai Lake, namely, Gangcha, Gonghe, Mengyuan, Xining, Guide, Guinan, Xinghai, Qilian, Tongren, and Dulan (Figure 1), were derived from the Dataset of Daily Climate Data from Chinese Surface Stations for Global Exchange (V3.0) released by the National Meteorological Information Center (NMIC) of the China Meteorological Administration (CMA) (http://data.cma.cn).

Due to the scarcity of direct in situ observations of lake surface water temperature (LSWT) in Qinghai Lake, we used the Land Surface Temperature 8-Day L3 Global (MOD11C2, MYD11C2, Level 3) product to verify LSWT simulated by WRF-FLake. The MOD11C2/MYD11C2 Version 6 product was derived from the data of Moderate Resolution Imaging Spectroradiometer (MODIS), installed on the Terra and Aqua sun-synchronous polar-orbiting satellites, by compositing and averaging the values from the corresponding eight MOD11C1/MYD11C1 daily files. The product provides the land surface temperature (LST) at a resolution of $0.05^{\circ}$ (5,600 $\mathrm{m}$ at the equator) latitude/longitude Climate Modeling Grid (CMG). Cloud-contaminated LSTs (daytime and nighttime) were removed from Level 2 and Level 3 LST products by a doublescreening method before reprojection. The accuracy is better than $1^{\circ} \mathrm{C}$ by using the day/night LST algorithm (Wan et al., 2002, 2004). Compared with previous versions, Version 6 of this product has been improved in accuracy (Wan, 2014).

To validate the simulated precipitation, we used data from the Tropical Rainfall Measuring Mission (TRMM) Multi-Satellite Precipitation Analysis (TMPA) 3B42 Version 7 daily product with $0.25^{\circ} \times 0.25^{\circ}$ horizontal spatial resolution (https://disc2.gesdisc.eosdis.nasa.gov/data/TRMM_L3/), covering the period from 3 April to 30 November 2013. TRMM is a joint mission of NASA and the Japan Aerospace Exploration Agency launched in 1997 to study rainfall for weather and climate research. TRMM provides critical precipitation information in tropical and subtropical regions over 17 years using several space-borne instruments, improving the understanding of the precipitation distribution and variability as part of the water cycle in the climate system. The TRMM has proven successful in approximately reproducing the surface observation as well as reasonably detecting large daily events (Huffman et al., 2007).

The National Centers for Environmental Prediction Global Final Analysis data (NCEP-FNL, http://rda.ucar. edu/datasets/ds083.2/) with a 6-h interval and $1^{\circ} \times 1^{\circ}$ horizontal resolution were used for setting initial and lateral boundary conditions in the model simulations. The data were adopted from the Global Data Assimilation System (GDAS), which continuously collects observational data from the Global Telecommunications System (GTS), and other sources. The FNL uses the same model as the NCEP Global Forecast System (GFS), with a delay about an hour behind the forecast, allowing assimilation of more observational data. 


\section{WRF Model}

We applied the WRF model Version 4.0 with the Advanced Research WRF dynamic core (Skamarock et al., 2008). WRF was developed by the National Center for Atmospheric Research (NCAR) and is widely used in both operational forecasting and research applications. WRF is a fully compressible, nonhydrostatic model using a terrain-following vertical coordinate system and multiple parameterization schemes.

The model was applied to a single domain with a horizontal resolution of $5 \mathrm{~km}$ and 35 vertical levels. The initial and lateral boundary conditions were generated from NCEP-FNL data, updated every $6 \mathrm{~h}$. Following the previous study on lake-affected precipitation over Nam Co Lake on the TP (Dai, Wang, et al., 2018), we adopted the following physics parameterizations: the Eta Ferrier microphysics, the rapid radiative transfer model (RRTM) for longwave radiation (Mlawer et al., 1997), the Dudhia shortwave radiation scheme (Dudhia, 1989), Revised MM5 surface layer scheme (Jimenez et al., 2012), the Noah land surface model, the Yonsei University (YSU) planetary boundary layer schemes (Hong et al., 2006), and the Betts-Miller-Janjic (BMJ) scheme for cumulus parameterization (Janjic, 1994). We excluded the ice-covered period from the simulations, taking into account acute errors produced by inaccurate lake ice predictions on the energy balance and LSWT (Eerola et al., 2010; Su et al., 2019): The simulations started on 3 April 2013 at 0000 UTC just after the lake ice melted and ended on 1 December 2013 at 0000 UTC before the lake is frozen. The initial LSWT was set to $274 \mathrm{~K}$ approximately according to the MODIS LST observations. The simulation results were stored every $3 \mathrm{~h}$. The approach comparing two numerical simulations, one including the lake and one without the lake, was applied following previous studies on the lake role in the climate system (Dai, Yao, et al., 2018; Farley Nicholls \& Toumi, 2014; Gu et al., 2016; Notaro et al., 2013; Thiery et al., 2015; Wen et al., 2015; Wu et al., 2019). Here, we performed a parallel simulation experiment, in which Qinghai Lake was replaced by the nearby land cover type with other model parameters kept unchanged. Hereinafter, we denote the simulation with Qinghai Lake as the control experiment (CTL) and the one without the Qinghai Lake as the no lake experiment (NOL).

To better incorporate the lake processes and lake-atmosphere interactions in regional climate systems, we applied the WRF version coupled to the lake model FLake (hereafter WRF-FLake) of Mallard et al. (2014). One of the advantages of the FLake is that only a small number of parameters need to be specified, the most important ones being the depth and the light extinction coefficient. Here, we set the lake depth to $21 \mathrm{~m}$ (the mean depth of Qinghai Lake). The water in Qinghai Lake is clear because of its oligotrophic state. Hence, the default WRF-FLake value of the extinction coefficient $\left(K_{d}\right)$ of $3 \mathrm{~m}^{-1}$ (corresponding to $\sim 0.5-\mathrm{m}$ Secchi disk depth [SDD] according to Arst et al., 2008; Zolfaghari et al., 2017) was found too large for Qinghai Lake. The study of Huang et al. (2019) proved that setting the light extinction coefficient to $0.1 \mathrm{~m}^{-1}$ instead of $3 \mathrm{~m}^{-1}$ can greatly improve the FLake performance at Nam Co Lake. After several offline tests of the FLake model for Qinghai Lake during the study period, we set the extinction coefficient to $0.35 \mathrm{~m}^{-1}$ (corresponding to SDD $\sim 7.5 \mathrm{~m}$ ), which was found to reasonably improve the model performance by reproducing a more accurate seasonal change of LSWT. To take into account the effect of salinity $\left(12.5 \mathrm{~g} \mathrm{~L}^{-1}\right.$ in Qinghai Lake) on vertical heat transport, the maximum density temperature of water $\left(T_{m}\right)$ was changed from 277.13 to $274.43 \mathrm{~K}$ and the water freezing point $\left(T_{f}\right)$ was changed from 273.15 to $272.46 \mathrm{~K}$ according to the linear approximations of the empirical function of the state of seawater (Caldwell, 1978; UNESCO, 1981) as follows:

$$
\begin{gathered}
T_{m}\left[{ }^{\circ} \mathrm{C}\right]=3.98-0.216 \mathrm{~S}, \\
T_{f}\left[{ }^{\circ} \mathrm{C}\right]=-0.055 \mathrm{~S},
\end{gathered}
$$

where S represents salinity $\left(\mathrm{g} \mathrm{L}^{-1}\right)$. The friction velocity $\left(u^{*}\right)$ was also doubled $\left(u^{*} \times 2\right)$ against the standard FLake parameterization to account for the wave-induced increase of the surface shear stress over the large lake surface (Z. Q. Gao et al., 2009) that significantly reduced the positive bias in the simulated LSWT. The adjustment of the friction velocity was previously tested in the application of the FLake and CLM-Lake model to Ngoring Lake by Song et al. (2020). 

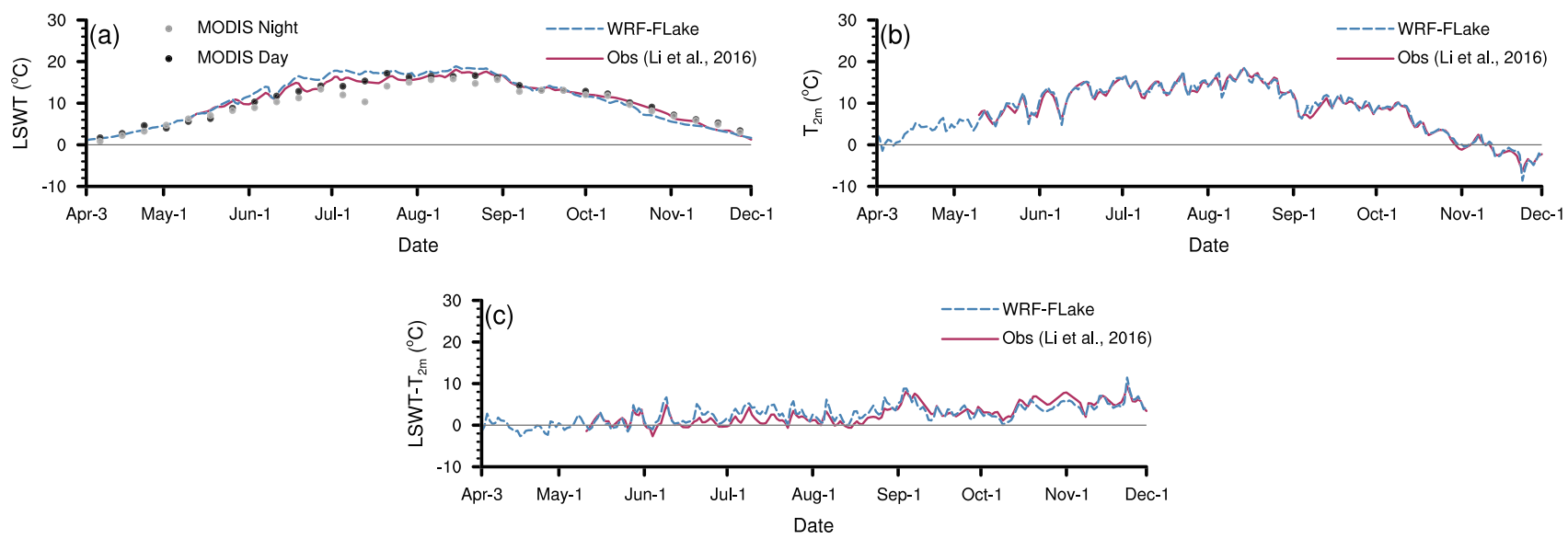

Figure 2. Comparison of daily (a) lake surface water temperature, (b) 2-m air temperature, and (c) lake-air temperature difference between WRF-FLake simulation and the observation by Li et al. (2016). The dots in figure (a) are lake surface temperatures obtained by MODIS.

\section{Results}

\subsection{Model Validation}

\subsubsection{LSWT and 2-m Air Temperature Evaluations}

Correct simulation of LSWT is crucial for the estimation of the lake effect on precipitation (X. Zhang et al., 2016). The daily averaged LSWT (Figure 2a) of Qinghai Lake simulated by the model (averaged over the entire lake surface) agreed well with the on-site observations from Li et al. (2016) and with MODIS data (a grid over the lake near the station). The on-site observations were measured at the platform of the China torpedo test base in southeastern Qinghai Lake by an infrared thermometer $\sim 10 \mathrm{~m}$ above the lake. The MODIS daily values were averaged from MOD11C2 and MYD11C2. The LSWT from MODIS was slightly lower (bias of $-0.54^{\circ} \mathrm{C}$ ) than the site observations, which may be related to the differences in the observation methods and scales, as well as to an uncompensated contribution of the "cool-skin" effect to the satellite data (Donlon et al., 2002). Against the station data, the simulated LSWT had a small warm bias of $0.44^{\circ} \mathrm{C}$, occasionally increasing in summer to $1.43^{\circ} \mathrm{C}$. The bias of the simulated LSWT against MODIS was $0.87^{\circ} \mathrm{C}$.

The simulated $T_{2}$ (averaged over all lake grid cells) and its daily variations were highly consistent with the observations of Li et al. (2016), with a slight warm bias of $0.21^{\circ} \mathrm{C}$ (Figure 2b), indicating that the WRF-FLake model can describe reasonably well the day-to-day $T_{2 \mathrm{~m}}$ variability over Qinghai Lake. The result also indirectly demonstrated the good ability of the coupled model to simulate the lake-atmosphere interaction in terms of LSWT influence on $T_{2 \mathrm{~m}}$ over the lake.

Correspondingly, the simulated lake-air temperature difference, which is the key characteristic determining the surface energy and mass transfer (Changnon \& Jones, 1972) and promoting thereby the lake-affected convective precipitation, was captured well by the WRF-FLake (Figure 2c). The average bias amounted at $0.36^{\circ} \mathrm{C}$; the model slightly overestimated the temperature difference in summer (bias of $1.44^{\circ} \mathrm{C}$ ), due to higher simulated LSWT in summer, but still reproduced correctly the persistently positive lake-air temperature difference over Qinghai Lake during the entire ice-free period.

\subsubsection{Precipitation Evaluation}

The modeled precipitation compared well against the TRMM observed data (Figure 3), demonstrating good model abilities in reproducing the spatial distribution of total precipitation in the simulation domain: The maximum precipitation occurred on the northeast of Qinghai Lake along the Qilian Mountain and in the southeast of the simulation domain, while the minimum of precipitation took place in the west. The WRF-FLake also captured the mostly positive correlation between precipitation and surrounding topography. Stronger precipitation was simulated along the Qilian Mountains, Qinghai South Mountains, and Riyue Mountains (Figure 3b) because the moist air condensed when lifted and cooled on the steep windward slopes. The result on the precipitation increase with elevation was consistent with previous findings from the TP regions (Geng et al., 2017; Navale \& Singh, 2020), proving the good ability of the model to simulate orographic precipitation. Compared to TRMM observation, the simulation tended to yield stronger 


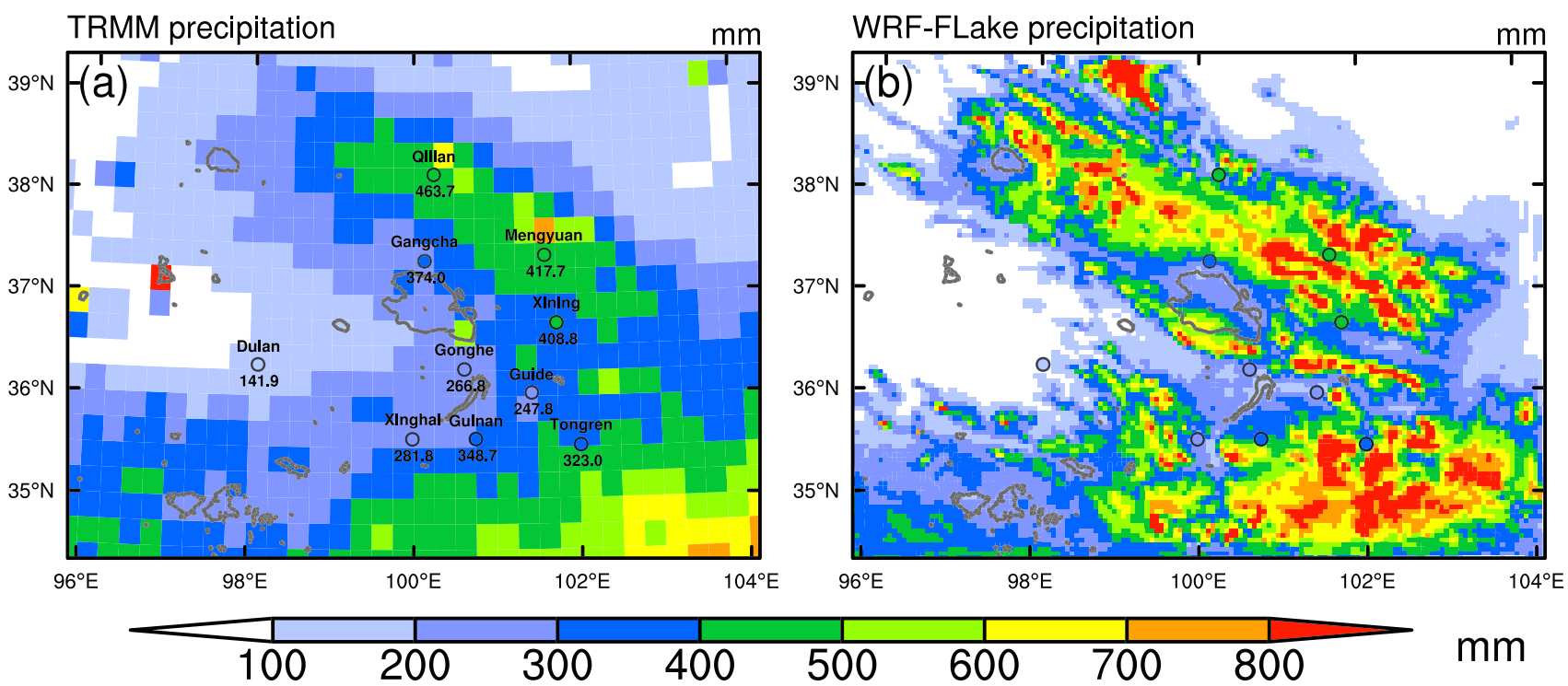

Figure 3. Spatial distributions of total precipitation from (a) TRMM and (b) WRF-FLake during the simulation period from 3 April to 30 November 2013. The black circles represent the location of the CMA stations, and the color in the circle represents the observed precipitation level.

precipitation over the high topography. The fact cannot be however ascribed completely to the simulation bias because the TRMM passive microwave radiometer may not adequately detect orographic precipitation over complex terrain areas (Bartsotas et al., 2018; Bharti \& Singh, 2015; Chen et al., 2013). Moreover, precipitation on the TP is indeed expected to occur mainly in the vicinity of the strong topographical gradients (Gerken et al., 2013; Navale \& Singh, 2020).

Despite in situ precipitation data from the CMA station network are very scarce, they are considered as the most accurate precipitation data set. Therefore, we used the CMA data to cross-validate both TRMM and simulated precipitation values (Figure 3). The results showed that precipitation obtained by TRMM is close to the in situ observations at the 10 selected stations with an average deviation of $-5.3 \mathrm{~mm}$ (Figure 3a). As shown in Table 1, TRMM underestimated precipitation at Xinghai $(-0.5 \mathrm{~mm})$, Dulan $(-19.9 \mathrm{~mm})$, Xining $(-50.3 \mathrm{~mm})$, Guinan $(-50.7 \mathrm{~mm})$, Qilian $(-51.2 \mathrm{~mm})$, and Gangcha $(-85.7 \mathrm{~mm})$, while overestimated it at Gonghe $(9.5 \mathrm{~mm})$, Mengyuan $(39.2 \mathrm{~mm})$, Tongren $(54.1 \mathrm{~mm})$, and Guide $(102.4 \mathrm{~mm})$.

The simulated precipitation was also close to the in situ observations with an average deviation of $-34.6 \mathrm{~mm}$ (Figure 3b). The simulated precipitation was larger than the CMA observations at Xinghai $(4.0 \mathrm{~mm})$, Mengyuan $(28.6 \mathrm{~mm})$, Tongren $(95.6 \mathrm{~mm})$, and Guinan $(117.4 \mathrm{~mm})$, while it is smaller at Gonghe (-48.1 mm), Xining $(-49.4 \mathrm{~mm})$, Dulan $(-62.1 \mathrm{~mm})$, Guide $(-72.0 \mathrm{~mm})$, Gangcha $(-89.3 \mathrm{~mm})$, and Qilian (-270.5 mm) (Table 1).

TRMM and WRF-FLake were in good agreement at Gangcha and Xining, but both underestimated precipitation compared to in situ observations. The TRMM results agreed well with the in situ precipitation at the Qilian and Gonghe stations, while the WRF-FLake significantly underestimated precipitation. Moreover, for some stations, such as Guide, the three data sets substantially differed from each other. The discrepancies between station observations, TRMM, and WRF-FLake simulations can be partly explained by their

Table 1

Total Precipitation From CMA Stations, TRMM, and WRF-FLake at the Location of 10 Selected Stations (Shown in Figure 3) During the Whole Simulation Period (Unit: $\mathrm{mm}$ )

\begin{tabular}{lcccccccccc}
\hline Station name & Gangcha & Gonghe & Mengyuan & Xining & Guide & Guinan & Xinghai & Qilian & Tongren & Dulan \\
\hline Station & 374.0 & 266.8 & 417.7 & 408.8 & 247.8 & 348.7 & 281.8 & 463.7 & 323.0 & 141.9 \\
TRMM & 288.3 & 276.3 & 456.9 & 358.5 & 350.2 & 298.0 & 281.3 & 412.5 & 377.1 & 122.0 \\
WRF-FLake & 284.7 & 218.7 & 446.3 & 359.4 & 175.8 & 466.1 & 285.8 & 193.2 & 418.6 & 79.8 \\
\hline
\end{tabular}



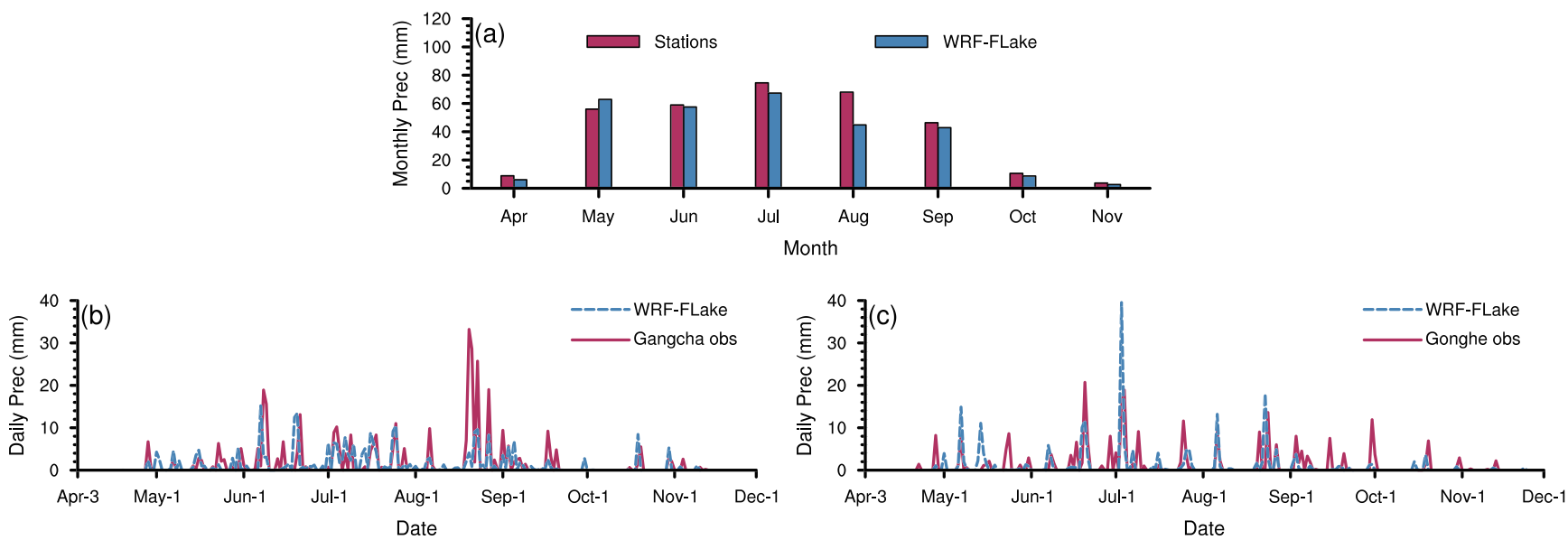

Figure 4. Comparison between WRF-FLake simulations and CMA station observations of (a) monthly precipitation averaged at all 10 stations, daily precipitation at (b) Gangcha station, and (c) Gonghe station.

different spatial resolutions. Due to the low spatial resolution, the TRMM 3B42 product cannot represent the small-scale changes, especially over the complex topography. Meantime, an accurate simulation of precipitation over complex terrain remains challenging, as demonstrated by the case of Qilian station.

Because the weather stations were located mostly in valleys and plains, it was not possible to verify precisely the precipitation produced by WRF-FLake over high-elevation areas. Only an indirect verification method through snow-cover fraction was recently employed by Y. Gao, Chen, and Jiang (2020). Nevertheless, the model demonstrated good accuracy in other regions confirmed by observations from land stations and TRMM.

The temporal variability of the simulated precipitation was also evaluated by comparison with CMA station observations (Figure 4). The simulated monthly precipitation averaged at the 10 selected stations was very close to the observation at those stations for most months with large precipitation ( $-2.4 \%$ in June, $-9.7 \%$ in July, $-7.5 \%$ in September); only in August, the simulated precipitation was much smaller $(-34.1 \%)$ than the land station observations (Figure 4a), mainly because the model underestimated the precipitation at Gangcha, Mengyuan, Xining, and Qilian stations.

To validate the simulated precipitation on the daily scale, the Gangcha and Gonghe stations, two of the nearest stations from Qinghai Lake, were chosen (Figures $4 \mathrm{~b}$ and $4 \mathrm{c}$ ). The results showed that the WRF-FLake model underestimated several precipitation events in late August at Gangcha station (Figure 4b) and overestimated one precipitation event in early July at Gonghe station (Figure 4c). Nevertheless, the model accurately captured the rest of the precipitation events during the simulation period from 3 April to 30 November 2013.

\subsection{Lake Effect on Local Precipitation}

The total precipitation difference between CTL and NOL experiments (Figure 5a) and its relative change (Figure 5b) during all simulation period showed that the presence of the Qinghai Lake increased the precipitation over the southern part of the lake and its adjacent land, while slightly reduced the precipitation over the northern part of the lake along its border. The area of the strongest precipitation increase, up to $326.3 \mathrm{~mm}$, was located close to the southwest end of the lake and extended over the land up to $20 \mathrm{~km}$ to the south, with an increase of more than $150 \mathrm{~mm}$. In turn, the existence of Qinghai Lake reduced precipitation at the lake's northern end up to $-112.6 \mathrm{~mm}$ compared with the NOL scenario. The relative precipitation change (CTL - NOL)/NOL (Figure 5b) shows that the precipitation increased up to $139.5 \%$ close to the southwest edge of the lake with 30-70\% increase extended to the land about 10-20 km away from the lake, while reduced down to $-34.2 \%$ over the area along the north shore of the lake.

The factors contributing to the nonuniform response of local precipitation to the presence of the lake may be related to the background wind and the orographic effect on the lake breeze over the southern side of Qinghai Lake. This will be considered in more detail through the dynamical response analysis in section 4.3. 

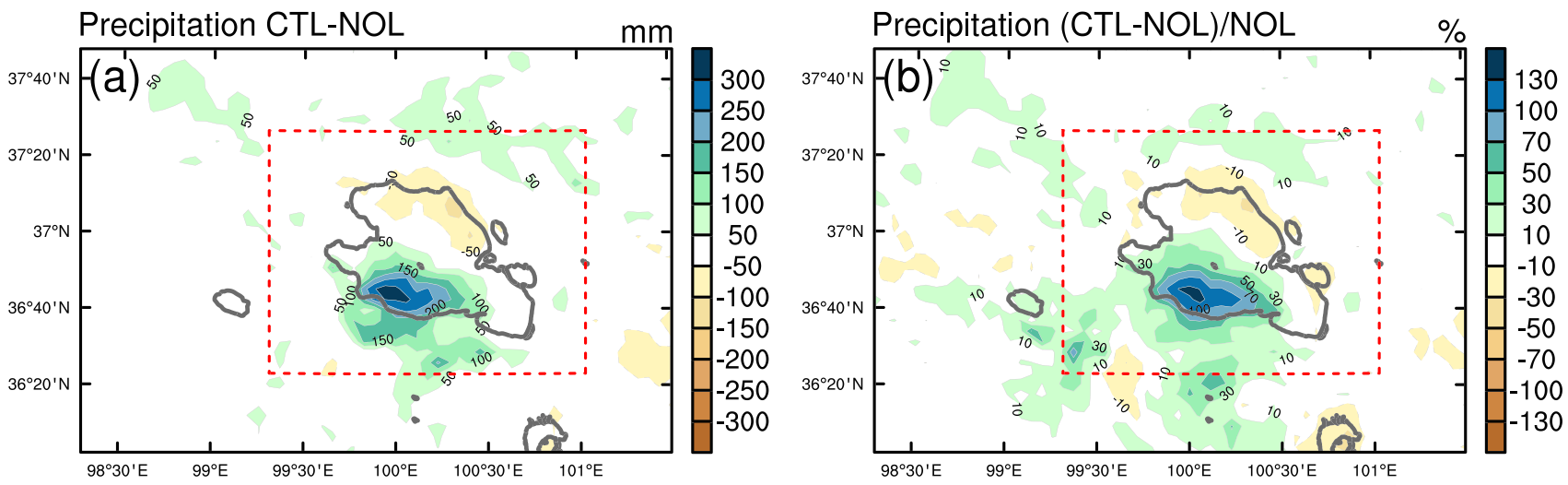

Figure 5. The spatial distribution of (a) precipitation difference (CTL - NOL) and (b) percent precipitation difference ((CTL - NOL)/NOL) between experiments with and without Qinghai Lake during the whole simulation period (from 3 April to 30 November 2013). The red dotted box represents the typical region of lake-effect precipitation. In panel (b), the grid points with precipitation close or equal to zero in NOL experiments were set to the missing value to avoid division by zero.

Figure 6a shows the monthly mean precipitation from the two experiments averaged over the lake and its surroundings (the red dotted box area in Figure 5): In the CTL experiment, the strongest precipitation within the lake region occurred in July, with descending values in August, June, September, and May, and very small precipitation in April, October, and November. In the NOL experiment, the amount of precipitation in different months was close to that in the CTL experiment, except for lower values in September. The precipitation difference between the two experiments (Figure 6b) indicated that the presence of Qinghai Lake slightly reduced the amount of regional precipitation in May and June by $-0.12(-6.6 \%)$ and $-0.11 \mathrm{~mm}^{-1 a y}{ }^{-1}$ $(-4.5 \%)$, respectively, while significantly increased precipitation from July to November: The highest increase took place in September $0.60 \mathrm{~mm}^{-1 a y}{ }^{-1}(40.4 \%)$, followed by $0.23 \mathrm{~mm}$ day ${ }^{-1}$ (9.1\%) in August, $0.21 \mathrm{~mm} \mathrm{day}^{-1}(5.7 \%)$ in July, $0.14 \mathrm{~mm} \mathrm{day}^{-1}$ (125.5\%) in October, and $0.09 \mathrm{~mm}$ day $^{-1}$ (125.6\%) in November. Noteworthy, the largest magnitude of the precipitation increase took place in September, but the relative precipitation change was at its maximum in November. Herewith, the lake effect appeared stronger in November despite the small absolute amount of lake-induced precipitation.

Based on the seasonality of the precipitation effect revealed above, we selected four representative months for further analysis on the spatial pattern and the diurnal variability of the lake effect on regional precipitation: June (similar to May), August (similar to July), September, and October (similar to November). The differences between the CTL and NOL experiments over the two periods of 11:00-20:00 BJT (Beijing Time, UTC + 8) and 23:00-08:00 BJT in a day were also averaged during the four selected months to study the lake's daytime and nighttime effect on precipitation separately.

In June (Figure 7a), Qinghai Lake weakly (down to $-62.8 \mathrm{~mm}$ ) reduced local precipitation over the northern part of the lake, while slightly and irregularly increased precipitation (maximum increase of $51.7 \mathrm{~mm}$ ) over the surrounding land. As Figure 7e shows, the daytime precipitation in June decreased over the entire lake while increased sporadically over the surrounding land. In the nighttime (Figure 7i), the precipitation
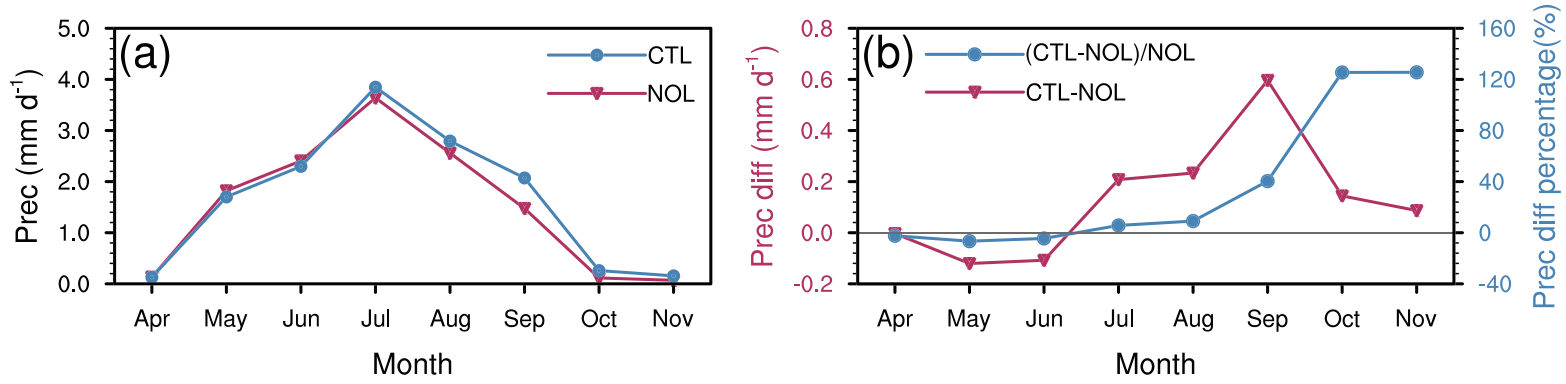

Figure 6. The monthly variation of (a) precipitation in CTL and NOL experiments and (b) precipitation absolute difference (CTL - NOL) and relative difference $((\mathrm{CTL}-\mathrm{NOL}) / \mathrm{NOL})$ between the two experiments averaged over all pixels across the lake area in the red dotted box in Figure 5. 

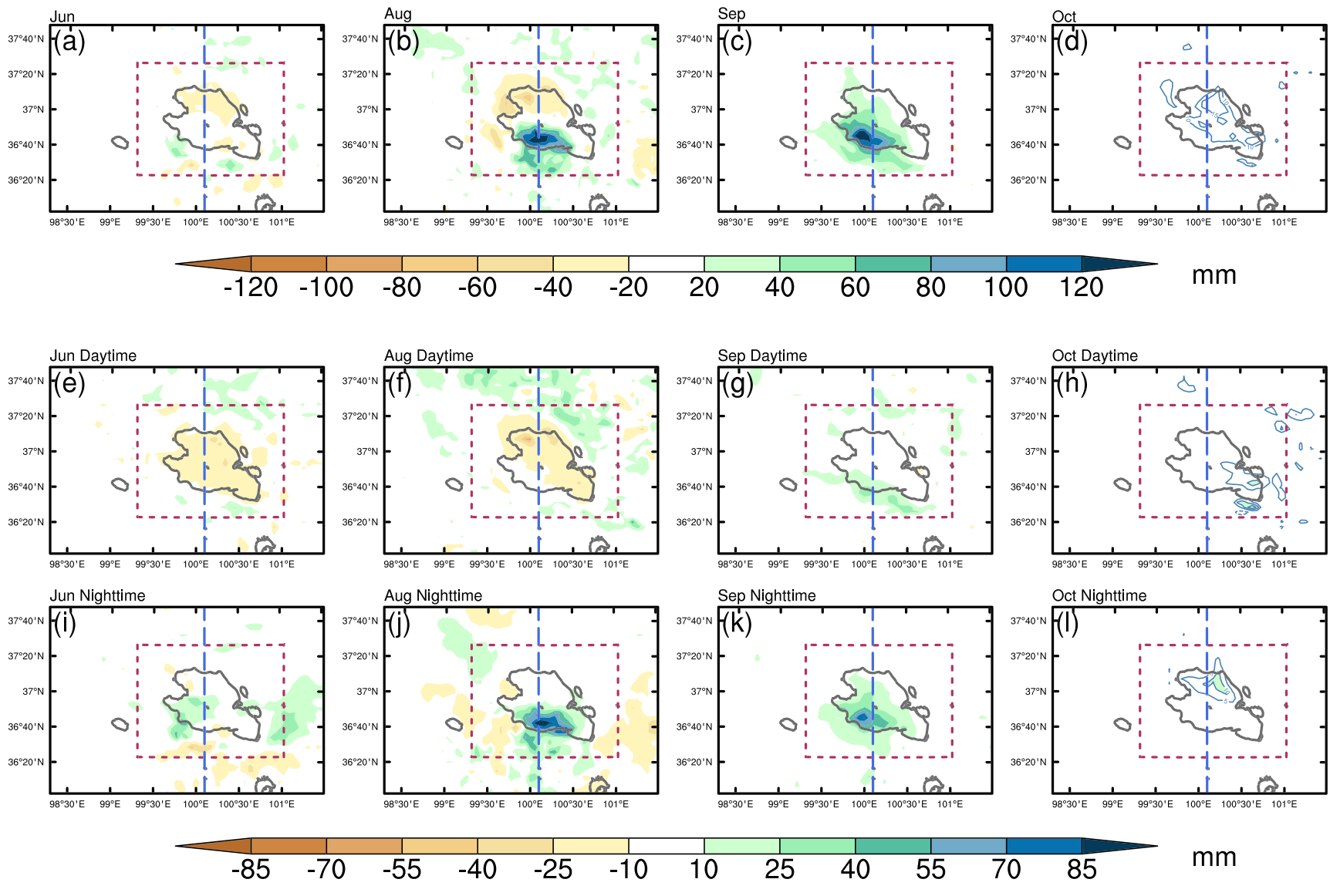

Figure 7. The spatial distribution of the monthly averaged precipitation difference between CTL and NOL experiments during (a-d) all day, (e-h) daytime (11:00-20:00 BJT), and (i-1) nighttime (23:00-08:00 BJT) in June (the first column), August (the second column), September (the third column), and October (the last column). The red dotted box represents the typical region of lake effect on precipitation; the blue dotted line represents the transection used for the vertical cross-section in Figure 9.

increased over the southwest and east parts of the lake but decreased over the land to the south. The spatial pattern of the precipitation difference between the two experiments was similar in July (not shown) and August (Figure 7b), but the difference was more obvious in August: The existence of Qinghai Lake increased the local precipitation over the southern portion of the lake and its adjacent land up to the maximum of $137.5 \mathrm{~mm}$ and slightly decreased precipitation (down to $-77.3 \mathrm{~mm}$ ) in the northwestern part of the lake and its adjacent land. The lake's influence on daytime precipitation in August (Figure 7f) was similar to that in June, except for a stronger precipitation increase over the northern land. During the nighttime (Figure 7j), precipitation was greatly enhanced over the southern part of the lake and the adjacent land but slightly decreased over the land at the west and east ends of the lake. In September, in contrast to the previous months, the lake produced a consistent increase of precipitation over the whole area (Figure 7c); the precipitation increase concentrated toward the southwestern part of the lake with a maximum of $147.5 \mathrm{~mm}$. In contrast to previous months, the daytime precipitation in September was not reduced but slightly increased along the southern shore of the lake (Figure 7g). Precipitation still increased over the south part of the lake in the nighttime, but no precipitation decrease was present over the surrounding land (Figure 7k). In October, the lake also increased precipitation over the entire lake (Figure 7d), contributed by the increased precipitation during daytime and nighttime (Figures $7 \mathrm{~h}$ and $7 \mathrm{l}$ ); the magnitude of increase (maximum value of $19.3 \mathrm{~mm}$ ) was negligible compared to that in September.

\subsection{Diurnal Cycle of Lake-Effect Precipitation and Its Mechanisms}

The diurnal variations of the mean difference between CTL and NOL in the selected months were calculated for local precipitation, surface temperature (LSWT), and 2-m air temperature $\left(T_{2 \mathrm{~m}}\right)$ over the lake (Figure 8). 

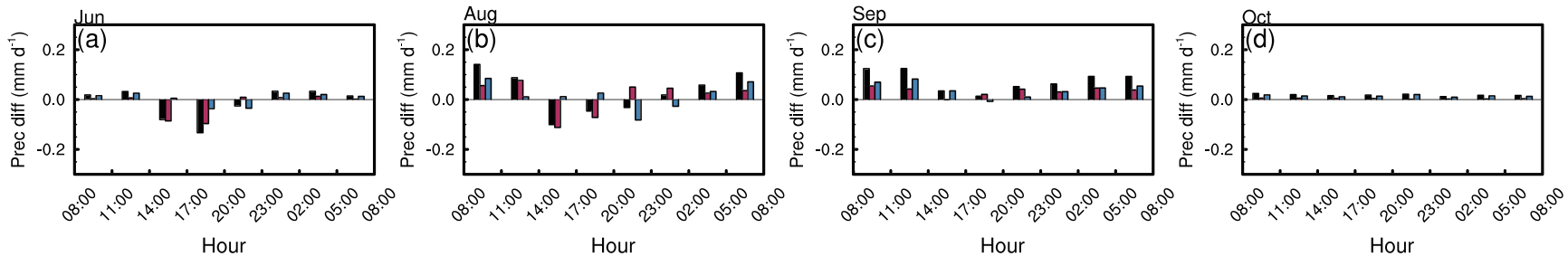

Total precipitation
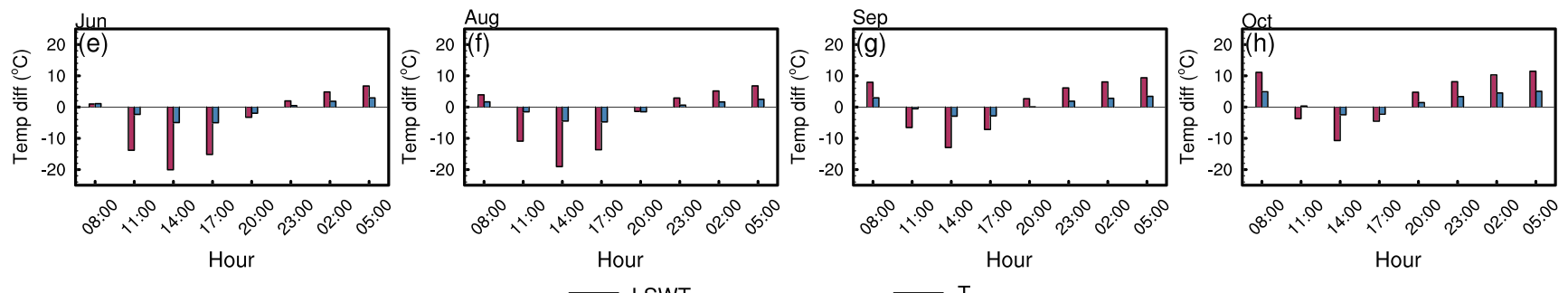

LSWT

$$
T_{2 m}
$$

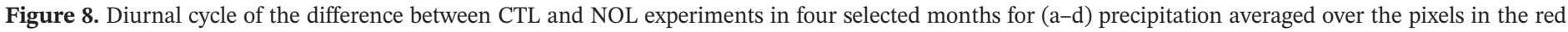
dotted box in Figure 7and (e-h) surface temperature (LSWT) and 2-m air temperature $\left(T_{2 \mathrm{~m}}\right)$ averaged over the pixels of Qinghai Lake.

The mechanism of the lake's precipitation effect was also further investigated by analyzing the cross-sections along $100.1^{\circ} \mathrm{E}$ in terms of the dynamical response of temperature, moisture, and atmospheric circulation to the lake presence for each selected month individually (Figure 9).

\subsubsection{Beginning of the Open Water Period (June)}

During the afternoon and evening hours (14:00-23:00 BJT), the presence of Qinghai Lake obviously reduced local precipitation, especially for convective precipitation (Figure 8a), due to the lake-induced daytime cooling effect (maximum of $-20.1^{\circ} \mathrm{C}$ for LSWT at $14: 00$ and $-5.0^{\circ} \mathrm{C}$ for $T_{2 \mathrm{~m}}$ at $17: 00$, Figure 8e). The latter resulted in the lake-land thermal contrast: The mountains around the lake warmed faster during the daytime because of the lower soil heat conductivity and the strong insolation, producing ascending motion over the surrounding land and formation of breeze circulation and downdraft over the lake (see the vertical transect for 14:00 BJT in Figure 9a). Consequently, the moisture from the lake, which can potentially destabilize
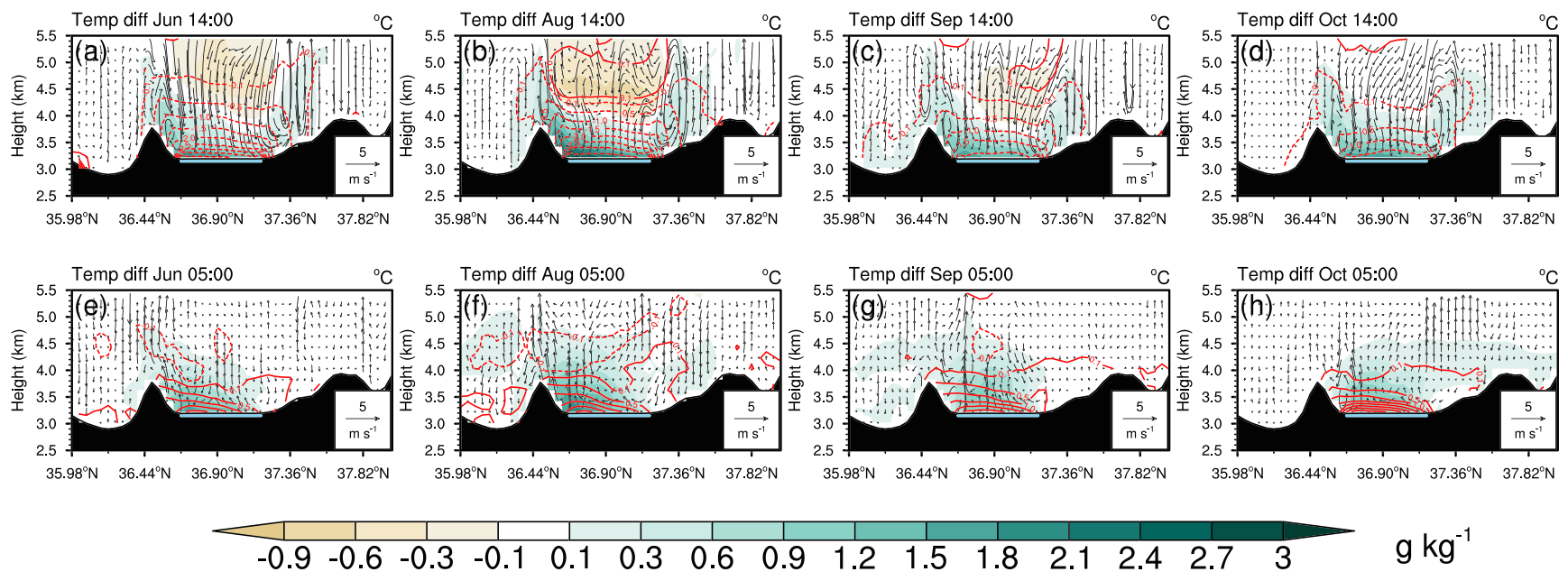

Figure 9. The height-latitude cross-sections along $100.1^{\circ} \mathrm{E}$ of the differences in the simulated air temperature (red line, solid is positive and dotted is negative), specific humidity (shaded), and longitudinal circulation (vectors) at (a-d) daytime (14:00 BJT, first row) and (e-h) nighttime (05:00 BJT, second row) averaged in four selected months; the vertical velocity scale is increased by a factor of 100 . The black shaded areas denote the terrain height. The sky-blue line represents the location of Qinghai Lake. 
the atmospheric boundary layer by releasing its latent heat to the air during condensation, was captured by the downdraft below $\sim 0.5 \mathrm{~km}$ above the lake surface. As a result, air humidity above $\sim 0.5 \mathrm{~km}$ reduced, forming a stable boundary layer over the lake. This secondary circulation with subsidence and divergent flow over the lake suppressed development of convective precipitation over the lake during the daytime but favored development of the over-land convective precipitation (Figure 7e) due to uphill moisture advection by the lake breeze to $\sim 1.7 \mathrm{~km}$ above lake level and subsequent destabilizing the atmospheric boundary layer (Figure 9a).

At night and morning hours (23:00-14:00 BJT), the lake rarely increased local precipitation (Figure 8a): The lake's nighttime warming effect was relatively weak (maximum of $6.8^{\circ} \mathrm{C}$ for LSWT at 05:00 and $2.9^{\circ} \mathrm{C}$ for $T_{2 \mathrm{~m}}$ at 05:00, Figure 8e), insufficient for a strong updraft and convection (Figure 9e). The air humidity increase by the lake was also too small to produce convective precipitation.

The diurnal variability was directly linked to the spatial distribution of the lake-affected precipitation in June shown above (Figure 7a): The daytime cooling effect of the lake, which decreased over-lake precipitation and increased over-land precipitation, was stronger than the nighttime warming effect. Hence, the nighttime precipitation increase was small and offset by the daytime decrease, resulting in reduced over-lake precipitation and increased over-land precipitation (Figure 7a).

\subsubsection{The Summer Heating Peak (August)}

During the afternoon and evening hours (14:00-23:00 BJT), the lake reduced local precipitation similarly to the June pattern, but at a smaller magnitude (Figure 8b). In August, a smaller daytime cooling effect (maximum of $-19.1^{\circ} \mathrm{C}$ for LSWT at $14: 00$ and $-4.8^{\circ} \mathrm{C}$ for $T_{2 \mathrm{~m}}$ at 17:00, Figure 8f) resulted in a weaker downdraft over the lake and, consequently, weaker damping of convective motions (Figure 9b). Additionally, despite the secondary circulation similar to that in June, the over-land updraft was stronger in August due to the stronger land heating by solar radiation (Figure 9b). The lake evaporation was also stronger in August; the moisture was advected by the lake breeze up to a height of $\sim 2 \mathrm{~km}$ above lake level following the ascending air motion (Figure 9b), destabilized the atmospheric boundary layer, and increased precipitation over the land. The lake-land thermal contrast was stronger over the south shore because of the steeper topography. As a result, the lake breeze advected more moisture southward, producing anabatic flow and stronger precipitation over the land to the south of the lake (Figure 7f).

At night and morning hours (23:00-14:00 BJT), the lake increased local precipitation compared to June (Figure 8b), because the warmer lake surface in August gradually warmed the atmospheric boundary layer (maximum of $6.8^{\circ} \mathrm{C}$ for LSWT at $05: 00$ and $2.5^{\circ} \mathrm{C}$ for $T_{2 \mathrm{~m}}$ at 05:00, Figure 8f). The warming strengthened the updraft and eventually lead to an outbreak of strong convective motion over the lake. Moreover, moisture provided by the lake evaporation further destabilized the lower atmosphere and increased precipitation. In contrast to the suppression effect of downdraft on moisten-caused boundary layer instability during the daytime, the nighttime warming effect reinforced this instability. Due to the opposite lake-land thermal contrast, the secondary circulation was reversed during nighttime (Figure 9f). The strong ascending motions over the lake raised the humid air up to $\sim 1.5 \mathrm{~km}$ above the lake. Concurrently, the downhill wind from the surrounding mountains advected the ambient air to the lake. By this, the air was further warmed and moistened by the lake, enhancing convection and increasing nighttime precipitation over the lake. Like in the daytime, the steeper topography in the south also lead to a stronger nighttime lake-land thermal contrast than in the north, but with the opposite sign. The temperature gradient generated a stronger land breeze and convergent airflow to the south of the lake, partially explaining the accumulated moisture and stronger lake-induced precipitation over the southern section of the lake (Figure 7j). The prevailing north direction of the background wind is another factor localizing the center of the convergence in the southern part of the lake (Figures 10a and 10b).

In general, the daytime cooling effect and nighttime warming effect of the lake both exert an important influence on local precipitation in August. During the daytime, the precipitation was reduced over the lake while slightly increased over the surrounding land, especially over the southern part. However, the over-lake precipitation was increased by the lake during nighttime, mostly over the south part of the lake, overwhelming the reduced daytime precipitation. Herewith, the spatial distribution of lake-affected precipitation in August showed a consistent pattern with a decrease in the north and an increase in the south (Figure 7b). 

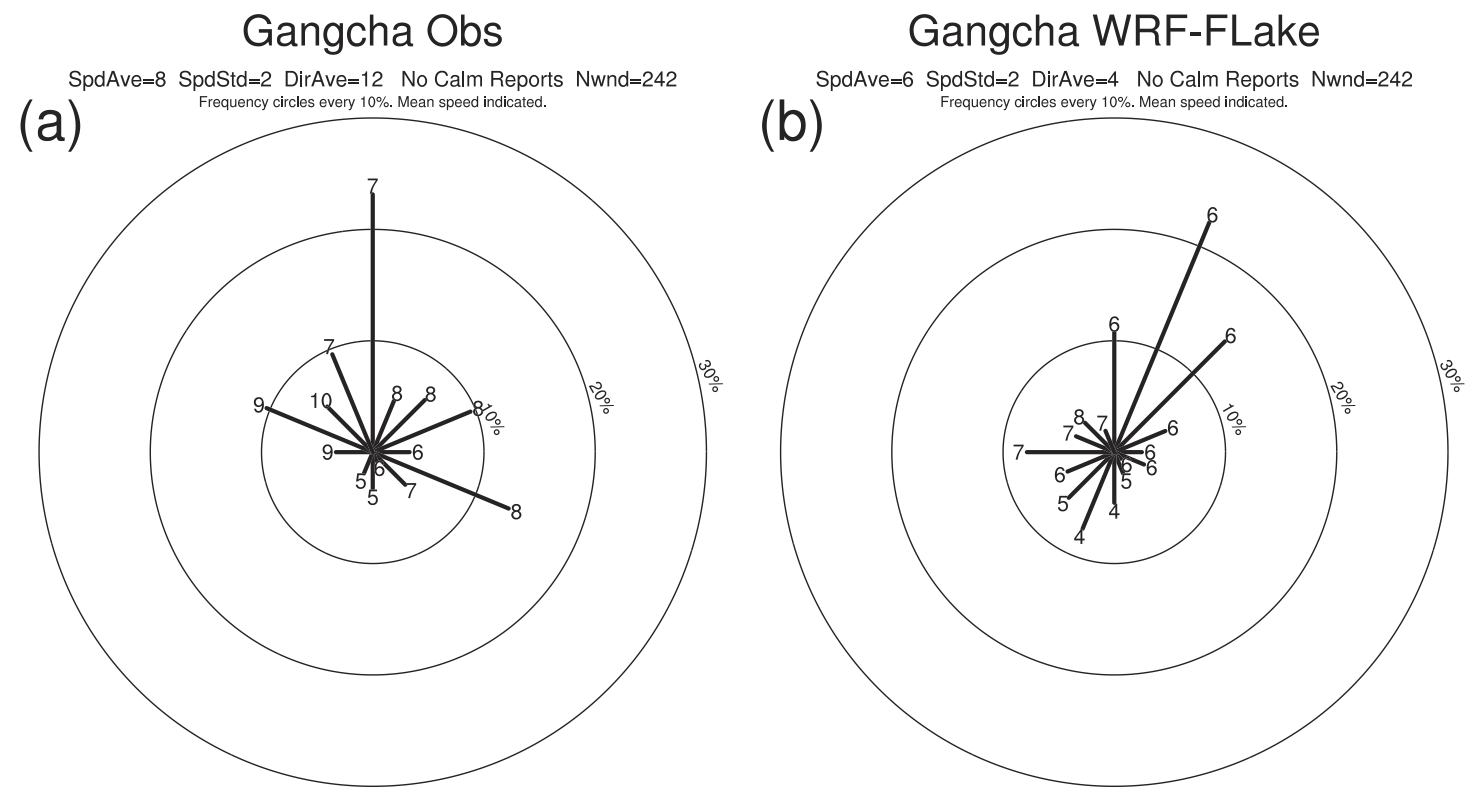

Figure 10. Wind Rose of the daily maximum wind from (a) observation and (b) WRF-FLake model at Gangcha Station during the simulation period. Each circle representing the frequency of a particular wind direction. The mean wind speed is shown at the end of each directional line.

\subsubsection{Start of the Autumn Cooling (September)}

At the afternoon and evening hours (14:00-23:00 BJT), the lake impact turns to a slight increase of the local precipitation, in contrast to the previous months (Figure 8c). The reason is twofold: On one hand, the daytime cooling effect of the lake weakened compared to August (maximum of $-12.9^{\circ} \mathrm{C}$ for LSWT at $14: 00$ and $-2.9^{\circ} \mathrm{C}$ for $T_{2 \mathrm{~m}}$ at 14:00, Figure $8 \mathrm{~g}$ ), making the downdraft over the lake too weak to inhibit convection. On the other hand, the weakening of the local thermal convection increased the contribution of the large-scale precipitation, which could not be inhibited by the lake's cooling effect, but was enhanced by the water vapor flux from the lake (Figure 9c).

At night and morning hours (23:00-14:00 BJT), the lake significantly increased local precipitation, similarly to August, especially for large-scale precipitation (Figure 8c). The nighttime warming effect of the lake (maximum of $9.4^{\circ} \mathrm{C}$ for LSWT at $05: 00$ and $3.4^{\circ} \mathrm{C}$ for $T_{2 \mathrm{~m}}$ at $05: 00$ ) was stronger than in August (Figure $8 \mathrm{~g}$ ), leading to a stronger updraft over the lake and facilitating intense convection (Figure 9g). The lake-induced increase of the water vapor supply to the boundary layer was less than in August, but sufficient to destabilize the lower atmosphere, to accelerate convective updraft up to $\sim 1.3 \mathrm{~km}$ above the lake through the latent heat released by condensation, and to enhance nighttime convective precipitation over the lake as well on the larger spatial scale (Figure 9g). Like in August, precipitation concentrated over the southern part of the lake due to topographic effects and the prevailing background wind from the north (Figure 7k).

In summary, while the lake's daytime cooling effect and its inhibition effect on precipitation weakened from August to September, the contribution of moisture from the lake to the precipitation enhancement remained significant. As a result, the lake effect on precipitation had changed from damping to a light enhancement. Besides, the strengthened nighttime warming effect favored convective precipitation. Herewith, precipitation began to increase during all day times in September.

\subsubsection{Late Autumn Before the Ice Cover Formation (October)}

At the afternoon and evening hours (14:00-23:00 BJT), the lake-induced increase of the local precipitation was negligible (Figure 8d). Compared to September, the lake-induced daytime cooling effect (maximum of $-10.7^{\circ} \mathrm{C}$ for LSWT at $14: 00$ and $-2.5^{\circ} \mathrm{C}$ for $T_{2 \mathrm{~m}}$ at $14: 00$ ) was further weakened in October (Figure $8 \mathrm{~h}$ ), as well as the downdraft and its suppression effect on convection over the lake (Figure 9d). Like in September, the lake increased moisture supply to the atmospheric boundary layer, favoring precipitation formed predominantly by large-scale systems. However, the lake-induced precipitation in October was much smaller than in September. 
At night and morning hours (23:00-14:00 BJT), the lake-induced precipitation was still small in absolute values (Figure $8 \mathrm{~d}$ ) but accounted for a large proportion compared with the no-lake scenario. The nighttime warming effect (maximum of $11.5^{\circ} \mathrm{C}$ for LSWT at 05:00 and $5.0^{\circ} \mathrm{C}$ for $T_{2 \mathrm{~m}}$ at 05:00) of the lake was the strongest compared to previous months (Figure 8h) and induced a considerable updraft over the lake. The increase of the air humidity by the lake was as strong as in September (Figure 9h), indicating a strong lake effect on local precipitation. However, the background atmospheric circulation was not favorable for the development of local precipitation and limited lake-induced precipitation.

The low amount but high proportion of lake-induced precipitation in October suggested that although the lake has a strong influence on local precipitation, the latter was still controlled by the background atmospheric circulation.

\section{Discussion}

Qinghai Lake demonstrated a significant influence on local precipitation pattern; however, it was different from that found in other studies on large lakes: Qinghai Lake consistently increased local precipitation from midsummer to autumn (July-November), whereas the Laurentian Great Lakes typically decrease local precipitation during summer (Notaro et al., 2013). The effect may be considered common for the high-elevation TP lakes: Studies on two other large Tibetan lakes (Ngoring and Nam Co) also demonstrated a significant lake-induced precipitation increase during the open water period (Dai, Wang, et al., 2018; Wen et al., 2015). The effect may apparently be attributed to low air temperatures and strong solar radiation at high altitudes, which allow the TP lakes to accumulate the solar heat and to maintain the positive lake-air temperature difference throughout the open water period, leading to intense evaporation from the lake surface due to convective cooling ( $\mathrm{Li}$ et al., 2015; Wang et al., 2015, 2017). With regard to the persistently unstable air-lake boundary layer, the air-lake interaction over the TP is similar to that over large tropical lakes (Verburg \& Antenucci, 2010). However, in contrast to the African Great Lakes at low latitudes, which generally cool the air over the lake in all seasons, the effect of midlatitude lakes, like Qinghai Lake, usually switches from cooling to warming in the course of the open water period (Thiery et al., 2015). Moreover, the former ones uniformly increase the annual precipitation mostly over lake surface (Thiery et al., 2015), while Qinghai Lake enhanced precipitation mainly over the southern section of the lake and its adjacent land (up to $326.3 \mathrm{~mm}, 139.5 \%$ ) but slightly reduced the precipitation along its north borderline (up to $-112.6 \mathrm{~mm}$, $-72.1 \%$ ). Due to a close relationship between precipitation and vegetation in the growing season (Fang et al., 2005; Wang et al., 2016), this spatial pattern of lake-effect precipitation can be indirectly reflected and verified by the vegetation distribution on the surrounding land, which is sparse on the northern shore of the Qinghai Lake but is abundant on its southern shore (Chen et al., 2011).

Large lake systems of temperate lowland regions, such as the Laurentian Great Lakes (Lofgren, 1997) and the "European Great Lakes" Ladoga and Onega (Eerola et al., 2014), increase drastically the local precipitation during late autumn and winter, remaining partially ice free due to their large heat capacity and enhancing heat and moisture fluxes to the cold atmosphere. The influence of the TP lakes on winter precipitation may, in turn, be assumed rather small due to the isolation of the lake surface by the seasonal ice cover. Therefore, the correct simulation of the ice-covered period is a crucial issue for lake models: While the incorporation of lake models substantially improved the ability of climate models to forecast the air-land interaction, a reliable simulation of the ice thermodynamics and mechanics remains challenging, resulting in substantial errors in ice-on and ice-off dates (Eerola et al., 2010; Xiao et al., 2016). All lakes of the TP are seasonally ice covered; hence, an unrealistic description of the lake surface state could impair simulation of the lake-air interaction as well as the cumulative lake effects on large spatial and temporal scales (Brown \& Duguay, 2010; Eerola et al., 2010; Su et al., 2019; Vavrus et al., 2013; Wright et al., 2013).

Despite all the TP lakes share common major drivers of the air-lake heat and mass exchange, there are also differences between the effects of the Qinghai Lake and other TP lakes on the local climate. Whereas Ngoring Lake (the largest freshwater lake on the TP) increased the local precipitation during the almost entire ice-free period, from April to October (Wen et al., 2015), Qinghai Lake reduced the local precipitation at the beginning of the open water period, in April-June. This fact may be ascribed to the altitudinal factor: The higher location ( 4,200 m a.s.l.) of the Ngoring Lake leads to a stronger contrast between the low air temperature and relatively high LSWT heated by solar radiation. 


\section{Conclusions}

In this study, we successfully simulated the effect of the Qinghai Lake on the regional precipitation during the ice-free period from 3 April to 30 November 2013 by using the WRF model coupled with the lake model FLake. As a prerequisite, four key parameters of FLake, the light extinction, the maximum density temperature, the freezing point, and the friction velocity, were adjusted to properly simulate conditions in a large brackish lake.

The comprehensive validation of the WRF-FLake against the MODIS LST, TRMM precipitation products, and land station observations demonstrated adequate representation of the simulated LSWT, $T_{2 \mathrm{~m}}$, and precipitation. The modeled values were consistent with observations from both in situ and MODIS, except a slight overestimation of LSWT in summer, which may be ascribed to uncertainties of both WRF and 1-D lake model FLake applied to a large lake with significant horizontal inhomogeneities. The spatial patterns of the simulated precipitation were highly consistent with TRMM observations. The simulated monthly precipitation at the 10 CMA stations around Qinghai Lake agreed well with the in situ observations. Verified by observations at Gangcha and Gonghe stations, the WRF-FLake model was able to capture well the precipitation events at daily scales.

The detailed analysis of the dynamical response of temperature, moisture, and atmospheric circulation to the lake presence revealed a complex lake effect on the local climate and its mechanisms at seasonal and daily scales. Generally, at daytime, the lake cools the air over the lake, resulting in the strengthening of the lake-land thermal contrast and generating over-land updrafts and over-lake subsidence. This circulation pattern prevents upward transport of water vapor from the lake and stabilizes the atmosphere over the lake. As a result, precipitation is suppressed over the lake while increases over the surrounding land. At nighttime, the thermal inertia of the lake produces warming of the over-lake air, causing an updraft over the lake and downdraft over the land, and supplying large amounts of moisture into the atmospheric boundary layer. These breeze effects cause a destabilization of the lower atmosphere, with the subsequent triggering of strong convection and enhanced precipitation over the lake. The aforementioned diurnal lake-driven effects on the local climate have been previously described in lakes both on the TP and other regions (Kristovich \& Spinar, 2005; Thiery et al., 2015; Wen et al., 2015; Wu et al., 2019). Our study extends the knowledge on the diurnal mechanisms by tracing its seasonal evolution: In the course of the open water period, the daytime cooling effect and, consequently, the suppression effect of the downdraft on convective motion weakened. Thus, the contribution of the lake-provided moisture to precipitation grew gradually, leading to a change of the lake's impact on precipitation from decreasing before September to slightly increasing afterward. In contrast to daytime, the nighttime warming effect strengthened gradually during the open water season, leading to an increase in the precipitation effect caused by the lake. The lake-induced precipitation enhancement was generally stronger from July to September than in October and November, indicating that the background large-scale atmospheric circulation may restrict the amount of lake-induced precipitation. The present study also indicated that the local topography and the prevailing wind direction may exert significant impacts on the climate effect of the lakes, while their specific contributions are still unclear and need further investigation.

\section{Data Availability Statement}

The daily air temperature and precipitation data from Chinese surface stations are available for purchase from the China Meteorological Data Service Center (CMDC, http://data.cma.cn/en/). We are grateful to the National Aeronautics and Space Administration (NASA) for providing the MODIS LST product and TRMM data (https://earthdata.nasa.gov/). The National Centers for Environmental Prediction Global Final Analysis (NCEP-FNL) data are available online (at https://rda.ucar.edu/datasets/ds083.2/).

This work was supported by the National Key Research and Development Program of China (2019YFE0197600), the bilateral research project GZ1259 of the Sino-German Center for Research Support, CAS "Light of West China” Program (Y929641001), the German Research Foundation (DFG Projects KI 853 13/1 and KI 853 16/1), and the National Key R\&D Program of China (2018YFB1502800).

\section{References}

Ao, Y., Lyu, S., Li, Z., Wen, L., \& Zhao, L. (2018). Numerical simulation of the climate effect of high-altitude lakes on the Tibetan Plateau. Sciences in Cold and Arid Regions, 10(5), 379-391.

Argent, R., Sun, X., Semazzi, F., Xie, L., \& Liu, B. (2015). The development of a customization framework for the WRF model over the Lake Victoria Basin, Eastern Africa on seasonal timescales. Advances in Meteorology, 15. https://doi.org/10.1155/2015/653473

Arst, H., Erm, A., Herlevi, A., Kutser, T., Lepparanta, M., Reinart, A., \& Virta, J. (2008). Optical properties of boreal lake waters in Finland and Estonia. Boreal Environment Research, 13(2), 133-158. 
Bartsotas, N. S., Anagnostou, E. N., Nikolopoulos, E. I., \& Kallos, G. (2018). Investigating satellite precipitation uncertainty over complex terrain. Journal of Geophysical Research: Atmospheres, 123, 5346-5359. https://doi.org/10.1029/2017JD027559

Bates, G. T., Giorgi, F., \& Hostetler, S. W. (1993). Toward the simulation of the effects of the Great Lakes on regional climate. Monthly Weather Review, 121(5), 1373-1387. https://doi.org/10.1175/1520-0493(1993)121<1373:Ttsote>2.0.Co;2

Bharti, V., \& Singh, C. (2015). Evaluation of error in TRMM 3B42V7 precipitation estimates over the Himalayan region. Journal of Geophysical Research: Atmospheres, 120, 12,458-12,473. https://doi.org/10.1002/2015JD023779

Bonan, G. B. (1995). Sensitivity of a GCM simulation to inclusion of inland water surfaces. Journal of Climate, 8(11), 2691-2704. https://doi. org/10.1175/1520-0442(1995)008<2691:SOAGST>2.0.CO;2

Brown, L. C., \& Duguay, C. R. (2010). The response and role of ice cover in lake-climate interactions. Progress in Physical Geography: Earth and Environment, 34(5), 671-704. https://doi.org/10.1177/0309133310375653

Cai, Y., Ke, C. Q., \& Duan, Z. (2017). Monitoring ice variations in Qinghai Lake from 1979 to 2016 using passive microwave remote sensing data. Science of the Total Environment, 607, 120-131. https://doi.org/10.1016/j.scitotenv.2017.07.027

Caldwell, D. R. (1978). Maximum density points of pure and saline water. Deep-Sea Research, 25(2), 175-181. https://doi.org/10.1016/01466291(78)90005-X

Chang, B., He, K. N., Li, R. J., Sheng, Z. P., \& Wang, H. (2017). Linkage of climatic factors and human activities with water level fluctuations in Qinghai Lake in the northeastern Tibetan Plateau, China. Water, 9(7), 13. https://doi.org/10.3390/w9070552

Changnon, S. A. (1961). Precipitation contrasts between the Chicago urban area and an offshore station in southern Lake Michigan. Bulletin of the American Meteorological Society, 42(1), 1-10. https://doi.org/10.1175/1520-0477-42.1.1

Changnon, S. A., \& Jones, D. M. A. (1972). Review of the influences of the Great Lakes on weather. Water Resources Research, 8(2), 360-371. https://doi.org/10.1029/WR008i002p00360

Chen, K. L., Han, Y. L., Cao, S. K., Ma, J., Cao, G. C., \& Lu, H. (2011). The study of vegetation carbon storage in Qinghai Lake Valley based on remote sensing and CASA model. Procedia Environmental Sciences, 10, 1568-1574. https://doi.org/10.1016/j. proenv.2011.09.249

Chen, S., Hong, Y., Cao, Q., Gourley, J. J., Kirstetter, P. E., Yong, B., et al. (2013). Similarity and difference of the two successive V6 and V7 TRMM multisatellite precipitation analysis performance over China. Journal of Geophysical Research: Atmospheres, 118, 13,060-13,074. https://doi.org/10.1002/2013JD019964

Chen, W. L., Sun, W. G., Zhou, J. N., \& Chen, J. (1995). A numerical simulation on lake-land breeze of Qinghai Lake. Journal of Lake Science, 7(4), 289-296. https://doi.org/10.18307/1995.0401

Cui, B. L., \& Li, X. Y. (2015). The impact of climate changes on water level of Qinghai Lake in China over the past 50 years. Hydrology Research. https://doi.org/10.2166/nh.2015.237

Cui, B. L., Xiao, B., Li, X. Y., Wang, Q., Zhang, Z. H., Zhan, C., \& Li, X. D. (2017). Exploring the geomorphological processes of Qinghai Lake and surrounding lakes in the northeastern Tibetan Plateau, using Multitemporal Landsat Imagery (1973-2015). Global and Planetary Change, 152, 167-175. https://doi.org/10.1016/j.gloplacha.2017.03.009

Dai, Y. F., Wang, L., Yao, T. D., Li, X. Y., Zhu, L. J., \& Zhang, X. W. (2018). Observed and simulated lake effect precipitation over the Tibetan Plateau: An initial study at Nam Co Lake. Journal of Geophysical Research: Atmospheres, 123, 6746-6759. https://doi.org/10.1029/ 2018JD028330

Dai, Y. F., Yao, T. D., Li, X. Y., \& Ping, F. (2018). The impact of lake effects on the temporal and spatial distribution of precipitation in the Nam Co basin, Tibetan Plateau. Quaternary International, 475, 63-69. https://doi.org/10.1016/j.quaint.2016.01.075

Deng, S. C., Dong, H. L., Lv, G., Jiang, H. C., Yu, B. S., \& Bishop, M. E. (2010). Microbial dolomite precipitation using sulfate reducing and halophilic bacteria: Results from Qinghai Lake, Tibetan Plateau, NW China. Chemical Geology, 278(3-4), 151-159. https://doi.org/ 10.1016/j.chemgeo.2010.09.008

Diallo, I., Giorgi, F., \& Stordal, F. (2018). Influence of Lake Malawi on regional climate from a double-nested regional climate model experiment. Climate Dynamics, 50(9-10), 3397-3411. https://doi.org/10.1007/s00382-017-3811-x

Dong, H. M., Song, Y. G., \& Zhang, M. S. (2019). Hydrological trend of Qinghai Lake over the last 60 years: Driven by climate variations or human activities? Journal of Water and Climate Change, 10(3), 524-534. https://doi.org/10.2166/wcc.2018.033

Donlon, C. J., Minnett, P. J., Gentemann, C., Nightingale, T. J., Barton, I. J., Ward, B., \& Murray, M. J. (2002). Toward improved validation of satellite sea surface skin temperature measurements for climate research. Journal of Climate, 15(4), 353-369. https://doi.org/10.1175/ 1520-0442(2002)015<0353:Tivoss > 2.0.Co;2

Dudhia, J. (1989). Numerical study of convection observed during the winter monsoon experiment using a mesoscale two-dimensional model. Journal of the Atmospheric Sciences, 46(20), 3077-3107. https://doi.org/10.1175/1520-0469(1989)046<3077:Nsocod>2.0.Co;2

Eerola, K., Rontu, L., Kourzeneva, E., Pour, H. K., \& Duguay, C. (2014). Impact of partly ice-free Lake Ladoga on temperature and cloudiness in an anticyclonic winter situation-A case study using a limited area model. Tellus A: Dynamic Meteorology and Oceanography, 66(1), 23929. https://doi.org/10.3402/tellusa.v66.23929

Eerola, K., Rontu, L., Kourzeneva, E., \& Shcherbak, E. (2010). A study on effects of lake temperature and ice cover in HIRLAM. Boreal Environment Research, 15(2), 130-142.

Fang, J. Y., Piao, S. L., Zhou, L. M., He, J. S., Wei, F. Y., Myneni, R. B., et al. (2005). Precipitation patterns alter growth of temperate vegetation. Geophysical Research Letters, 32, L21411. https://doi.org/10.1029/2005GL024231

Farley Nicholls, J., \& Toumi, R. (2014). On the lake effects of the Caspian Sea. Quarterly Journal of the Royal Meteorological Society, 140(681), 1399-1408. https://doi.org/10.1002/qj.2222

Gao, Y., Chen, F., \& Jiang, Y. (2020). Evaluation of a convection-permitting modeling of precipitation over the Tibetan Plateau and its influences on the simulation of snow-cover fraction. Journal of Hydrometeorology, 21(7), 1531-1548. https://doi.org/10.1175/jhm-d-190277.1

Gao, Y., Chen, F., Miguez-Macho, G., \& Li, X. (2020). Understanding precipitation recycling over the Tibetan Plateau using tracer analysis with WRF. Climate Dynamics, 55(9-10), 2921-2937. https://doi.org/10.1007/s00382-020-05426-9

Gao, Y. X., Tang, M. C., Luo, S. W., Shen, Z. B., \& Li, C. (1981). Some aspects of recent research on the Qinghai-Xizang Plateau meteorology. Bulletin of the American Meteorological Society, 62(1), 31-35. https://doi.org/10.1175/1520-0477(1981)062<0031: Saorro $>2.0 . \mathrm{Co} ; 2$

Gao, Z. Q., Wang, Q., \& Zhou, M. Y. (2009). Wave-dependence of friction velocity, roughness length, and drag coefficient over coastal and open water surfaces by using three databases. Advances in Atmospheric Sciences, 26(5), 887-894. https://doi.org/10.1007/s00376-0098130-7

Geng, H. P., Pan, B. T., Huang, B., Cao, B., \& Gao, H. S. (2017). The spatial distribution of precipitation and topography in the Qilian Shan Mountains, northeastern Tibetan Plateau. Geomorphology, 297, 43-54. https://doi.org/10.1016/j.geomorph.2017.08.050 
Gerken, T., Biermann, T., Babel, W., Herzog, M., Ma, Y., Foken, T., \& Graf, H.-F. (2013). A modelling investigation into lake-breeze development and convection triggering in the Nam Co Lake basin, Tibetan Plateau. Theoretical and Applied Climatology, 117(1-2), 149-167. https://doi.org/10.1007/s00704-013-0987-9

Gu, H. P., Jin, J. M., Wu, Y. H., Ek, M. B., \& Subin, Z. M. (2015). Calibration and validation of lake surface temperature simulations with the coupled WRF-lake model. Climatic Change, 129(3-4), 471-483. https://doi.org/10.1007/s10584-013-0978-y

Gu, H. P., Ma, Z. G., \& Li, M. X. (2016). Effect of a large and very shallow lake on local summer precipitation over the Lake Taihu basin in China. Journal of Geophysical Research: Atmospheres, 121, 8832-8848. https://doi.org/10.1002/2015JD024098

Gula, J., \& Peltier, W. R. (2012). Dynamical downscaling over the Great Lakes basin of North America using the WRF regional climate model: The impact of the Great Lakes system on regional greenhouse warming. Journal of Climate, 25(21), 7723-7742. https://doi.org/ 10.1175/Jcli-D-11-00388.1

Hong, S. Y., Noh, Y., \& Dudhia, J. (2006). A new vertical diffusion package with an explicit treatment of entrainment processes. Monthly Weather Review, 134(9), 2318-2341. https://doi.org/10.1175/mwr3199.1

Hostetler, S. W., Bates, G. T., \& Giorgi, F. (1993). Interactive coupling of a lake thermal-model with a regional climate model. Journal of Geophysical Research, 98(D3), 5045-5057. https://doi.org/10.1029/92JD02843

Huang, A., Wang, J., Dai, Y., Yang, K., Wei, N., et al. (2019). Evaluating and improving the performance of three 1-D lake models in a large deep lake of the central Tibetan Plateau. Journal of Geophysical Research: Atmospheres, 124, 3143-3167. https://doi.org/10.1029/ 2018JD029610

Huffman, G. J., Bolvin, D. T., Nelkin, E. J., Wolff, D. B., Adler, R. F., Gu, G., et al. (2007). The TRMM multisatellite precipitation analysis (TMPA): Quasi-global, multiyear, combined-sensor precipitation estimates at fine scales. Journal of Hydrometeorology, 8(1), 38-55. https://doi.org/10.1175/Jhm560.1

Iakunin, M., Salgado, R., \& Potes, M. (2018). Breeze effects at a large artificial lake: Summer case study. Hydrology and Earth System Sciences, 22(10), 5191-5210. https://doi.org/10.5194/hess-22-5191-2018

Janjic, Z. I. (1994). The step-mountain eta coordinate model-Further developments of the convection, viscous sublayer, and turbulence closure schemes. Monthly Weather Review, 122(5), 927-945. https://doi.org/10.1175/1520-0493(1994)122<0927:TSMECM>2.0.CO;2

Jimenez, P. A., Dudhia, J., Gonzalez-Rouco, J. F., Navarro, J., Montavez, J. P., \& Garcia-Bustamante, E. (2012). A revised scheme for the WRF surface layer formulation. Monthly Weather Review, 140(3), 898-918. https://doi.org/10.1175/mwr-d-11-00056.1

Jiusto, J. E., \& Kaplan, M. L. (1972). Snowfall from lake-effect storms. Monthly Weather Review, 100(1), 62. https://doi.org/10.1175/15200493(1972)100<0062:Sfls >2.3.Co;2

Kirillin, G. (2010). Modeling the impact of global warming on water temperature and seasonal mixing regimes in small temperate lakes. Boreal Environment Research, 15(2), 279-293.

Kirillin, G., Hochschild, J., Mironov, D., Terzhevik, A., Golosov, S., \& Nützmann, G. (2011). FLake-Global: Online lake model with worldwide coverage. Environmental Modelling \& Software, 26(5), 683-684. https://doi.org/10.1016/j.envsoft.2010.12.004

Kristovich, D. A. R., \& Spinar, M. L. (2005). Diurnal variations in lake-effect precipitation near the Western Great Lakes. Journal of Hydrometeorology, 6(2), 210-218. https://doi.org/10.1175/Jhm403.1

Kristovich, D. A. R., Young, G. S., Verlinde, J., Sousounis, P. J., Mourad, P., Lenschow, D., et al. (2000). The lake-induced convection experiment and the snowband dynamics project. Bulletin of the American Meteorological Society, 81(3), 519-542. https://doi.org/10.1175/ 1520-0477(2000)081<0519:TLCEAT>2.3.CO;2

Le Moigne, P., Colin, J., \& Decharme, B. (2016). Impact of lake surface temperatures simulated by the FLake scheme in the CNRM-CM5 climate model. Tellus A: Dynamic Meteorology and Oceanography, 68(1). https://doi.org/10.3402/tellusa.v68.31274

Lei, Y. B., Yang, K., Wang, B., Sheng, Y. W., Bird, B. W., Zhang, G. Q., \& Tian, L. D. (2014). Response of inland lake dynamics over the Tibetan Plateau to climate change. Climatic Change, 125(2), 281-290. https://doi.org/10.1007/s10584-014-1175-3

Li, X. Y., Ma, Y. J., Huang, Y. M., Hu, X., Wu, X. C., Wang, P., et al. (2016). Evaporation and surface energy budget over the largest high-altitude saline lake on the Qinghai-Tibet Plateau. Journal of Geophysical Research: Atmospheres, 121, 10,470-10,485. https://doi. org/10.1002/2016JD025027

Li, Z. G., Lyu, S. H., Ao, Y. H., Wen, L. J., Zhao, L., \& Wang, S. Y. (2015). Long-term energy flux and radiation balance observations over Lake Ngoring, Tibetan Plateau. Atmospheric Research, 155, 13-25. https://doi.org/10.1016/j.atmosres.2014.11.019

Liao, J. J., Shen, G. Z., \& Li, Y. K. (2013). Lake variations in response to climate change in the Tibetan Plateau in the past 40 years. International Journal of Digital Earth, 6(6), 534-549. https://doi.org/10.1080/17538947.2012.656290

Lofgren, B. M. (1997). Simulated effects of idealized Laurentian Great Lakes on regional and large-scale climate. Journal of Climate, 10(11), 2847-2858. https://doi.org/10.1175/1520-0442(1997)010<2847:Seoilg >2.0.Co;2

Long, Z., Perrie, W., Gyakum, J., Caya, D., \& Laprise, R. (2007). Northern lake impacts on local seasonal climate. Journal of Hydrometeorology, 8(4), 881-896. https://doi.org/10.1175/Jhm591.1

Lv, Y. Q., Yang, X. Y., \& Ma, Y. M. (2007). Numerical simulation of summer circulation and atmospheric boundary layer characteristics over Qinghai Lake. Plateau Meteorology, 26(4), 686-692.

Ma, R. H., Yang, G. S., Duan, H. T., Jiang, J. H., Wang, S. M., Feng, X. Z., et al. (2010). China's lakes at present: Number, area and spatial distribution. Science China Earth Sciences, 54(2), 283-289. https://doi.org/10.1007/s11430-010-4052-6

Ma, Y., Wang, Y., Wu, R., Hu, Z., Yang, K., Li, M., et al. (2009). Recent advances on the study of atmosphere-land interaction observations on the Tibetan Plateau. Hydrology and Earth System Sciences, 13(7), 1103-1111. https://doi.org/10.5194/hess13-1103-2009

Mallard, M. S., Nolte, C. G., Bullock, O. R., Spero, T. L., \& Gula, J. (2014). Using a coupled lake model with WRF for dynamical downscaling. Journal of Geophysical Research: Atmospheres, 119, 7193-7208. https://doi.org/10.1002/2014JD021785

Mironov, D. V. (2008). Parameterization of lakes in numerical weather prediction. Description of a lake model. (COSMO Technical Report, Nol 11, p. 41). Germany: Deutscher Wetterdienst, Offenbach am Main.

Mlawer, E. J., Taubman, S. J., Brown, P. D., Iacono, M. J., \& Clough, S. A. (1997). Radiative transfer for inhomogeneous atmospheres: RRTM, a validated correlated-k model for the longwave. Journal of Geophysical Research, 102(D14), 16,663-16,682. https://doi.org/ 10.1029/97JD00237

Navale, A., \& Singh, C. (2020). Topographic sensitivity of WRF-simulated rainfall patterns over the North West Himalayan region. Atmospheric Research, 242(15). https://doi.org/10.1016/j.atmosres.2020.105003

Notaro, M., Holman, K., Zarrin, A., Fluck, E., Vavrus, S., \& Bennington, V. (2013). Influence of the Laurentian Great Lakes on regional climate. Journal of Climate, 26(3), 789-804. https://doi.org/10.1175/Jcli-D-12-00140.1

Samuelsson, P., Kourzeneva, E., \& Mironov, D. (2010). The impact of lakes on the European climate as simulated by a regional climate model. Boreal Environment Research, 15(2), 113-129. 
Scott, R. W., \& Huff, F. A. (1996). Impacts of the Great Lakes on regional climate conditions. Journal of Great Lakes Research, 22(4), 845-863. https://doi.org/10.1016/S0380-1330(96)71006-7

Skamarock, W. C., Klemp, J. B., Dudhia, J., Gill, D. O., Barker, D. M., Wang, W., \& Powers, J. G. (2008). A description of the Advanced Research WRF version 3. NCAR Technical note-475 + STR.

Song, X. Y., Wen, L. J., Li, M. S., Du, J., Su, D. S., Yin, S. C., \& Lv, Z. (2020). Comparative study on applicability of different lake models to typical lakes in Qinghai-Tibetan Plateau. Plateau Meteorology, 39(2), 213-225. https://doi.org/10.7522/j.issn.1000-0534.2019.00102

Su, D. S., Hu, X. Q., Wen, L. J., Lyu, S. H., Gao, X. Q., Zhao, L., et al. (2019). Numerical study on the response of the largest lake in China to climate change. Hydrology and Earth System Sciences, 23(4), 2093-2109. https://doi.org/10.5194/hess-23-2093-2019

Subin, Z. M., Riley, W. J., \& Mironov, D. (2012). An improved lake model for climate simulations: Model structure, evaluation, and sensitivity analyses in CESM1. Journal of Advances in Modeling Earth Systems, 4, M02001. https://doi.org/10.1029/2011MS000072

Theeuwes, N. E., Steeneveld, G. J., Krikken, F., \& Holtslag, A. A. M. (2010). Mesoscale modeling of lake effect snow over Lake ErieSensitivity to convection, microphysics and the water temperature. Advances in Science and Research, 4, 15-22. https://doi.org/10.5194/ asr-4-15-2010

Thiery, W., Davin, E. L., Panitz, H. J., Demuzere, M., Lhermitte, S., \& van Lipzig, N. (2015). The impact of the African Great Lakes on the regional climate. Journal of Climate, 28(10), 4061-4085. https://doi.org/10.1175/Jcli-D-14-00565.1

UNESCO (1981). The practical salinity scale1978 and the international equation of state of seawater 1980. UNESCO Technical Paper Marine Science, 36

Vavrus, S., Notaro, M., \& Zarrin, A. (2013). The role of ice cover in heavy lake-effect snowstorms over the Great Lakes Basin as simulated by RegCM4. Monthly Weather Review, 141(1), 148-165. https://doi.org/10.1175/mwr-d-12-00107.1

Verburg, P., \& Antenucci, J. P. (2010). Persistent unstable atmospheric boundary layer enhances sensible and latent heat loss in a tropical great lake: Lake Tanganyika. Journal of Geophysical Research, 115, D11109. https://doi.org/10.1029/2009JD012839

Wan, Z., Zhang, Y., Zhang, Q., \& Li, Z. L. (2004). Quality assessment and validation of the MODIS global land surface temperature. International Journal of Remote Sensing, 25(1), 261-274. https://doi.org/10.1080/0143116031000116417

Wan, Z. M. (2014). New refinements and validation of the collection-6 MODIS land-surface temperature/emissivity product. Remote Sensing of Environment, 140, 36-45. https://doi.org/10.1016/j.rse.2013.08.027

Wan, Z. M., Zhang, Y. L., Zhang, Q. C., \& Li, Z. L. (2002). Validation of the land-surface temperature products retrieved from Terra Moderate Resolution Imaging Spectroradiometer data. Remote Sensing of Environment, 83(1-2), 163-180. https://doi.org/10.1016/S00344257(02)00093-7

Wang, B. B., Ma, Y. M., Chen, X. L., Ma, W. Q., Su, Z. B., \& Menenti, M. (2015). Observation and simulation of lake-air heat and water transfer processes in a high-altitude shallow lake on the Tibetan Plateau. Journal of Geophysical Research: Atmospheres, 120, 12,327-12,344. https://doi.org/10.1002/2015JD023863

Wang, B. B., Ma, Y. M., Ma, W. Q., \& Su, Z. B. (2017). Physical controls on half-hourly, daily, and monthly turbulent flux and energy budget over a high-altitude small lake on the Tibetan Plateau. Journal of Geophysical Research: Atmospheres, 122, 2289-2303. https://doi.org/ 10.1002/2016JD026109

Wang, X. L., Liang, T. G., Xie, H. J., Huang, X. D., \& Lin, H. L. (2016). Climate-driven changes in grassland vegetation, snow cover, and lake water of the Qinghai Lake basin. Journal of Applied Remote Sensing, 10(3), 036017. https://doi.org/10.1117/1.Jrs.10.036017

Wen, L. J., Lv, S. H., Li, Z. G., Zhao, L., \& Nagabhatla, N. (2015). Impacts of the two biggest lakes on local temperature and precipitation in the Yellow River source region of the Tibetan Plateau. Advances in Meteorology, 10. https://doi.org/10.1155/2015/248031

Wilson, J. W. (1977). Effect of Lake-Ontario on precipitation. Monthly Weather Review, 105(2), 207-214. https://doi.org/10.1175/1520-0493 (1977)105<0207:Eoloop>2.0.Co;2

Wright, D. M., Posselt, D. J., \& Steiner, A. L. (2013). Sensitivity of lake-effect snowfall to lake ice cover and temperature in the Great Lakes region. Monthly Weather Review, 141(2), 670-689. https://doi.org/10.1175/Mwr-D-12-00038.1

Wu, Y., Huang, A. N., Yang, B., Dong, G. T., Wen, L. J., Zhang, Z., et al. (2019). Numerical study on the climatic effect of the lake clusters over Tibetan Plateau in summer. Climate Dynamics, 53(9-10), 5215-5236. https://doi.org/10.1007/s00382-019-04856-4

Xiao, C. L., Lofgren, B. M., Wang, J., \& Chu, P. Y. (2016). Improving the lake scheme within a coupled WRF-lake model in the Laurentian Great Lakes. Journal of Advances in Modeling Earth Systems, 8, 1969-1985. https://doi.org/10.1002/2016MS000717

Xu, X. D., Lu, C. G., Shi, X. H., \& Gao, S. T. (2008). World water tower: An atmospheric perspective. Geophysical Research Letters, 35, L20815. https://doi.org/10.1029/2008GL035867

Xue, P. F., Pal, J. S., Ye, X. Y., Lenters, J. D., Huang, C. F., \& Chu, P. Y. (2017). Improving the simulation of large lakes in regional climate modeling: Two-way Lake-atmosphere coupling with a 3D hydrodynamic model of the Great Lakes. Journal of Climate, 30(5), $1605-1627$. https://doi.org/10.1175/Jcli-D-16-0225.1

Zhang, G. Q., Xie, H. J., Duan, S. Q., Tian, M. Z., \& Yi, D. H. (2011). Water level variation of Lake Qinghai from satellite and in situ measurements under climate change. Journal of Applied Remote Sensing, 5(1). https://doi.org/10.1117/1.3601363

Zhang, G. Q., Yao, T. D., Xie, H. J., Zhang, K. X., \& Zhu, F. J. (2014). Lakes' state and abundance across the Tibetan Plateau. Chinese Science Bulletin, 59(24), 3010-3021. https://doi.org/10.1007/s11434-014-0258-x

Zhang, X., Duan, K. Q., Shi, P. H., \& Yang, J. H. (2016). Effect of lake surface temperature on the summer precipitation over the Tibetan Plateau. Journal of Mountain Science, 13(5), 802-810. https://doi.org/10.1007/s11629-015-3743-Z

Zolfaghari, K., Duguay, C. R., \& Pour, H. K. (2017). Satellite-derived light extinction coefficient and its impact on thermal structure simulations in a 1-D lake model. Hydrology and Earth System Sciences, 21(1), 377-391. https://doi.org/10.5194/hess-21-377-2017 